\title{
The Drosophila Receptor Protein Tyrosine Phosphatase LAR Is Required for Development of Circadian Pacemaker Neuron Processes That Support Rhythmic Activity in Constant Darkness But Not during Light/Dark Cycles
}

\author{
Parul Agrawal and Paul E. Hardin \\ Department of Biology and Center for Biological Clocks Research, Texas A\&M University, College Station, Texas 77845-3258
}

In Drosophila, a transcriptional feedback loop that is activated by CLOCK-CYCLE (CLK-CYC) complexes and repressed by PERIODTIMELESS (PER-TIM) complexes keeps circadian time. The timing of CLK-CYC activation and PER-TIM repression is regulated posttranslationally, in part through rhythmic phosphorylation of CLK, PER, and TIM. Although kinases that control PER, TIM, and CLK levels, activity, and/or subcellular localization have been identified, less is known about phosphatases that control clock protein dephosphorylation. To identify clock-relevant phosphatases, clock-cell-specific RNAi knockdowns of Drosophila phosphatases were screened for altered activity rhythms. One phosphatase that was identified, the receptor protein tyrosine phosphatase leukocyte-antigen-related (LAR), abolished activity rhythms in constant darkness (DD) without disrupting the timekeeping mechanism in brain pacemaker neurons. However, expression of the neuropeptide pigment-dispersing factor (PDF), which mediates pacemaker neuron synchrony and output, is eliminated in the dorsal projections from small ventral lateral $\left(\mathrm{sLN}_{\mathrm{v}}\right)$ pacemaker neurons when Lar expression is knocked down during development, but not in adults. Loss of Lar function eliminates $\operatorname{sLN}_{\mathrm{v}}$ dorsal projections, but PDF expression persists in $\operatorname{sLN}_{\mathrm{v}}$ and large ventral lateral neuron cell bodies and their remaining projections. In contrast to the defects in lights-on and lights-off anticipatory activity seen in flies that lack PDF, Lar RNAi knockdown flies anticipate the lights-on and lights-off transition normally. Our results demonstrate that $L a r$ is required for $\mathrm{SLN}_{\mathrm{v}}$ dorsal projection development and suggest that PDF expression in $\mathrm{LN}_{\mathrm{v}}$ cell bodies and their remaining projections mediate anticipation of the lights-on and lights-off transitions during a light/dark cycle.

Key words: circadian rhythms; clock genes; locomotor activity; neuropeptides; pacemaker neurons; phosphatase

\section{Significance Statement}

In animals, circadian clocks drive daily rhythms in physiology, metabolism, and behavior via transcriptional feedback loops. Because key circadian transcriptional activators and repressors are regulated by phosphorylation, we screened for phosphatases that alter activity rhythms when their expression was reduced. One such phosphatase, leukocyte-antigen-related (LAR), abolishes activity rhythms, but does not disrupt feedback loop function. Rather, Lar disrupts clock output by eliminating axonal processes from clock neurons that release pigment-dispersing factor (PDF) neuropeptide into the dorsal brain, but PDF expression persists in their cell bodies and remaining projections. In contrast to flies that lack PDF, flies that lack Lar anticipate lights-on and lights-off transitions normally, which suggests that the remaining PDF expression mediates activity during light/dark cycles.

\section{Introduction}

A diverse array of animals, plants and microbes display daily rhythms in physiology, metabolism, and/or behavior. These

This work was supported by National Institutes of Health Grant NS052854. We thank Michael Rosbash for PER antibody raised in rabbit, Amita Sehgal for TIM antibody raised in rat, Jeff Price for the UAS-Dicer2;timGal4 and w;UAS-Dicer2;pdfGal4 strains, and Vivek M. Agrawal for his help in writing MATLAB scripts to generate histograms using the ClockLab software. rhythms are not passively driven by environmental cycles, but are controlled by endogenous circadian $(\sim 24 \mathrm{~h})$ clocks that keep time in the absence of environmental cues. Circadian clocks in eukaryotes keep time via one or more transcriptional feedback loops that drive daily rhythms in their gene expression. In Dro- 
Table 1. Activity rhythms are disrupted in clock-cell-specific Lar RNAi knockdown and Lar mutant flies

\begin{tabular}{|c|c|c|c|c|}
\hline Genotype & Total & Rhythmic, \% & Period \pm SEM & Strength \pm SEM \\
\hline$w^{1118} ;+;+$ & 16 & 100 & $23.50 \pm 0.00$ & $160.34 \pm 21.62$ \\
\hline$w^{1118} ;$ timGal4/+;+ & 16 & 88 & $23.54 \pm 0.04$ & $129.26 \pm 11.33$ \\
\hline$w^{1118} ;+; p d f G a l 4 /+$ & 16 & 100 & $23.66 \pm 0.06$ & $118.24 \pm 14.20$ \\
\hline$w^{1118 ; \text { UAS-LarRNAi/ +;+ }}$ & 16 & 100 & $23.53 \pm 0.03$ & $26.44 \pm 9.06$ \\
\hline$w^{1118} ;$,UAS-LarRNAi/timGal4;+ & 12 & 25 & $24.17 \pm 0.27$ & $8.68 \pm 1.25^{*}$ \\
\hline$w^{1118 ;}$,UAS-LarRNAi/+;pdfGal4/+ & 16 & 0 & n.a. & $2.20 \pm 1.03^{*}$ \\
\hline UAS-Dicer2;timGal4/+;+ & 16 & 100 & $24.81 \pm 0.12$ & $=12.26$ \\
\hline UAS-Dicer2;UAS-LarRNAi/timGal4;+ & 11 & 0 & n.a. & $5.00 \pm 1.43^{*}$ \\
\hline$w^{1118} ;$ UAS-Dicer2/+;pdfGal4/+ & 15 & 80 & $24.17 \pm 0.09$ & $62.66 \pm 11.51$ \\
\hline $\begin{array}{l}w^{11118} ; \text { UAS-Dicer2/UAS-LarRNAi; } \\
\text { pdfGal4/+ }\end{array}$ & 10 & 10 & 23.50 & $5.78 \pm 1.22^{*}$ \\
\hline$w^{1118} ; \operatorname{Lar}^{13.2} /+;+$ & 14 & 93 & $23.54 \pm 0.04$ & $59.37 \pm 3.23$ \\
\hline$w^{1118} ;$ Lar Df/+;+ & 14 & 100 & $23.71 \pm 0.11$ & $113.54 \pm 29.01$ \\
\hline$w^{1118} ;$ Lar Df $/ L a r^{13.2} ;+$ & 14 & 0 & n.a. & $1.83 \pm 0.17^{\#}$ \\
\hline
\end{tabular}

Adult males were entrained in LD for $3 \mathrm{~d}$ and transferred to $\mathrm{DD}$ for at least $7 \mathrm{~d}$. Analysis of activity rhythms in $\mathrm{DD}$ and fly genotypes are as described in Materials and Methods. Total, Number of animals tested; Rhythmic \%, percentage of rhythmic animals; Period \pm SEM, rhythm period in hours \pm SEM; Strength \pm SEM, robustness of activity rhythms \pm SEM.

${ }^{*}$ Rhythm strength is significantly different $(p<0.01)$ than $w^{1118}$ and controls containing either the Gal4 driver or UAS responder alone with or without Dicer2.

${ }^{\#}$ Rhythm strength is significantly different $(p<0.001)$ than $w^{1118}, w^{1118} ;$ Lar Df/ +; + , and $w^{1118} ;$ Lar ${ }^{13.2} /+;+$ flies.

sophila, the core timekeeping loop is initiated by CLOCK-CYCLE (CLK-CYC) heterodimers, which activate period (per) and timeless (tim) transcription. Accumulating levels of PER and TIM proteins inhibit CLK-CYC activity, and once PER and TIM are degraded, the next round of CLK-CYC activation can begin (Hardin, 2011). Transcriptional feedback loops driven by orthologous transcriptional regulators function in other animals including humans, indicating that the timekeeping mechanism is highly conserved (Hardin and Panda, 2013; Partch et al., 2014).

The Drosophila circadian clock operates in many cells and tissues (Menet and Hardin, 2014). In the brain, this feedback loop operates in $\sim 75$ pacemaker neurons per hemisphere that function to drive activity rhythms (Helfrich-Förster, 2003). These brain pacemaker neurons can be divided into multiple clusters based on their location, size and neuropeptide expression, including two anterior dorsal neuron $1 \mathrm{~s}\left(\mathrm{DN}_{1 \mathrm{a}} \mathrm{s}\right), \sim 15$ posterior dorsal neuron 1s $\left(\mathrm{DN}_{1 \mathrm{p}} \mathrm{s}\right)$, two dorsal neuron $2 \mathrm{~s}\left(\mathrm{DN}_{2} \mathrm{~s}\right), \sim 38$ dorsal neuron $3 \mathrm{~s}\left(\mathrm{DN}_{3} \mathrm{~s}\right)$, six dorsal lateral neurons $\left(\mathrm{LN}_{\mathrm{d}} \mathrm{s}\right)$, three lateral posterior neurons (LPNs), four pigment-dispersing factor (PDF) neuropeptide-expressing small ventral lateral neurons $\left(\mathrm{sLN}_{\mathrm{v}} \mathrm{s}\right)$, one PDF-negative $s \mathrm{SN}_{\mathrm{v}}$, and four large ventral lateral neurons $\left(\mathrm{lLN}_{\mathrm{v}} \mathrm{s}\right.$; Nitabach and Taghert, 2008; Shafer and Yao, 2014). These clusters of pacemaker neurons form a network that maintains synchrony and determines the pattern of activity rhythms based on environmental inputs (Peschel and HelfrichFörster, 2011; Yoshii et al., 2012). This network also exhibits circadian plasticity; the PDF-positive $\mathrm{sLN}_{\mathrm{v}} \mathrm{s}$ send axonal projections toward $\mathrm{DN}_{1} \mathrm{~s}$ and $\mathrm{DN}_{2} \mathrm{~s}$ that undergo daily changes in morphology (Fernández et al., 2008). However, a direct molecular link between the core clock and rhythmic remodeling of $s \mathrm{LN}_{\mathrm{v}}$ axonal projections has not been identified.

The timing of CLK-CYC activation and PER-TIM repression is primarily regulated post-translationally, in part through rhythmic phosphorylation of CLK, PER and TIM to generate $\sim 24 \mathrm{~h}$ rhythms. Many kinases have been identified that control PER, TIM, and CLK levels, activity, and/or subcellular localization (Kloss et al., 1998, 2001; Price et al., 1998; Martinek et al., 2001; Lin et al., 2002; Akten et al., 2003, 2009; Chiu et al., 2011; Yu et al., 2011; Szabó et al., 2013). In contrast, few phosphatases have been discovered that target PER, TIM, and/or CLK to regulate transcriptional rhythms (Sathyanarayanan et al., 2004; Fang et al., 2007; Andreazza et al., 2015). To identify additional phosphatases that function within the Drosophila circadian clock, we screened for phosphatases that disrupt activity rhythms upon RNAi knockdown in clock cells.

Of 22 phosphatases with aberrant rhythms, the receptor protein tyrosine phosphatase (RPTP) leukocyte-antigen related (LAR; Streuli et al., 1989), is required for rhythmic activity. Despite this behavioral arrhythmicity, clock protein rhythms persist in brain pacemaker neurons from Lar mutants and RNAi knockdown flies, which suggest that Lar mediates clock output. Indeed, PDF accumulation in $\mathrm{SLN}_{\mathrm{v}}$ dorsal projections is eliminated in Lar mutant and RNAi knockdown flies, but PDF expression persists in $s \mathrm{SN}_{\mathrm{v}}$ cell bodies. The lack of PDF accumulation in $\mathrm{sLN}_{\mathrm{v}}$ dorsal projections in Lar mutant and RNAi knockdown flies is due to defects in the arborization of these projections during development. Unlike flies deficient in PDF expression or PDF neurons, which lack lights-on anticipation and show premature lights-off anticipation (Renn et al., 1999), Lar RNAi knockdown flies show normal lights-on and lights-off anticipation. Because PDF expression in $\mathrm{SLN}_{\mathrm{v}}$ and $\mathrm{LN}_{\mathrm{v}}$ cell bodies and their surviving projections distinguish Lar mutants and RNAi knockdown flies from flies lacking PDF entirely, our results suggest that the remaining PDF expression in $\mathrm{sLN}_{\mathrm{v}}$ and $\mathrm{ILN}_{\mathrm{v}} \mathrm{s}$ mediate lights-on and lightsoff anticipation during light/dark cycles.

\section{Materials and Methods}

Fly strains. The following Drosophila strains were used in this study: $w^{1118}, w^{1118} ;$ Cyo/Sco;TM2/TM6B,$w^{1118} ;$ tim Gal4, $w^{1118} ;$; $d f$ Gal4, w; timGal4, UAS-LarRNAi (P\{KK100581\}, VDRC), UAS-Lar ( $w$; $\mathrm{P}\{\mathrm{UAS}-$ Lar.K\}P4B, BDSC), UAS-Dicer2;timGal4, and w;UAS-Dicer2;pdfGal4 (gifts from Jeffery Price, University of Missouri, Kansas City MO), UAS-mCD8::GFP ( $w$;P\{UAS-mCD8::GFP.L $\} L L 6$, BDSC), tubGal80 $0^{\text {ts }}$ (P\{tubP-Gal80 $\left.{ }^{\text {ts }}\right\} 20$, BDSC), Lar $^{13.2}$ ( $w ;$ Lar $^{13.2} /$ CyO, BDSC), Lar Df (Df(2L)E55, rdo ${ }^{1} h_{o o k}{ }^{1}$ Lar $^{\mathrm{E} 55} \mathrm{pr}^{1} / \mathrm{CyO}, \mathrm{BDSC}$ ), and $y w ; ; p d f^{01}$ (a gift from Paul Taghert Washington University, St. Louis, MO). Flies were reared on standard cornmeal/agar medium supplemented with yeast and kept in $12 \mathrm{~h}$ light $/ 12 \mathrm{~h}$ dark (LD) cycles at $25^{\circ} \mathrm{C}$. The Lar mutant strains, Lar $^{13.2}$ and Lar Df were backcrossed seven times to $y^{1} ; \mathrm{P}$ \{SUPor$\mathrm{P}\} \mathrm{Lar}^{\mathrm{KG} 04810} / \mathrm{CyO} ; r^{506}$ flies (BDSC) to minimize effects due to differences in genetic background.

Drosophila activity monitoring and behavior analysis. One- to 3-d-old male flies were entrained for $3 \mathrm{~d}$ in LD cycles and transferred to constant darkness (DD) for $7 \mathrm{~d}$ at $25^{\circ} \mathrm{C}$. To knockdown Lar only in adults using the TARGET system (McGuire et al., 2003), $w^{1118}$;UAS-LarRNAi/ tubGal $80^{\text {ts }} ; p d f \mathrm{Gal} 4 /+$ males were raised at the permissive temperature $\left(18^{\circ} \mathrm{C}\right)$ for $t u b \mathrm{Gal} 80^{\text {ts }}$ to block Gal4-dependent expression of Lar RNAi. After eclosion, flies were entrained for $3 \mathrm{~d}$ in $\mathrm{LD}$ and monitored for $7 \mathrm{~d}$ in $\mathrm{DD}$ at the restrictive temperature $\left(30^{\circ} \mathrm{C}\right)$, which allows Gal4-dependent expression of Lar RNAi. Controls lacking Lar expression in adults and during development were raised and tested at $18^{\circ} \mathrm{C}$. To express Lar RNAi only during development, $w^{1118}$;UAS-LarRNAi/tubGal $80^{\text {ts }} ; p d f G a l 4 /+$ males were raised at $30^{\circ} \mathrm{C}$ to allow Gal4-dependent Lar RNAi expression. After eclosion, flies were entrained for $3 \mathrm{~d}$ in $\mathrm{LD}$ and monitored for $7 \mathrm{~d}$ in $\mathrm{DD}$ at the permissive temperature $\left(18^{\circ} \mathrm{C}\right)$. Controls that express Lar during development and in adults were raised and tested at $30^{\circ} \mathrm{C}$. Locomotor activity was monitored using the Drosophila Activity Monitor system (Trikinetics). To determine period and rhythm strength during DD, $\chi^{2}$ periodogram analysis was performed using ClockLab (Actimetrics) software as previously described (Pfeiffenberger et al., 2010). Flies were considered rhythmic if their $\chi^{2}$ power value was $\geq 10$ above the significance line (ie, strength $\geq 10$ ) and they were clearly rhythmic by visual inspection of the actogram. For analysis of activity during LD conditions, flies were monitored for $7 \mathrm{~d}$. The number of activity events were recorded in $30 \mathrm{~min}$ bins, and average numbers of activity events per $30 \mathrm{~min}$ bin per fly 

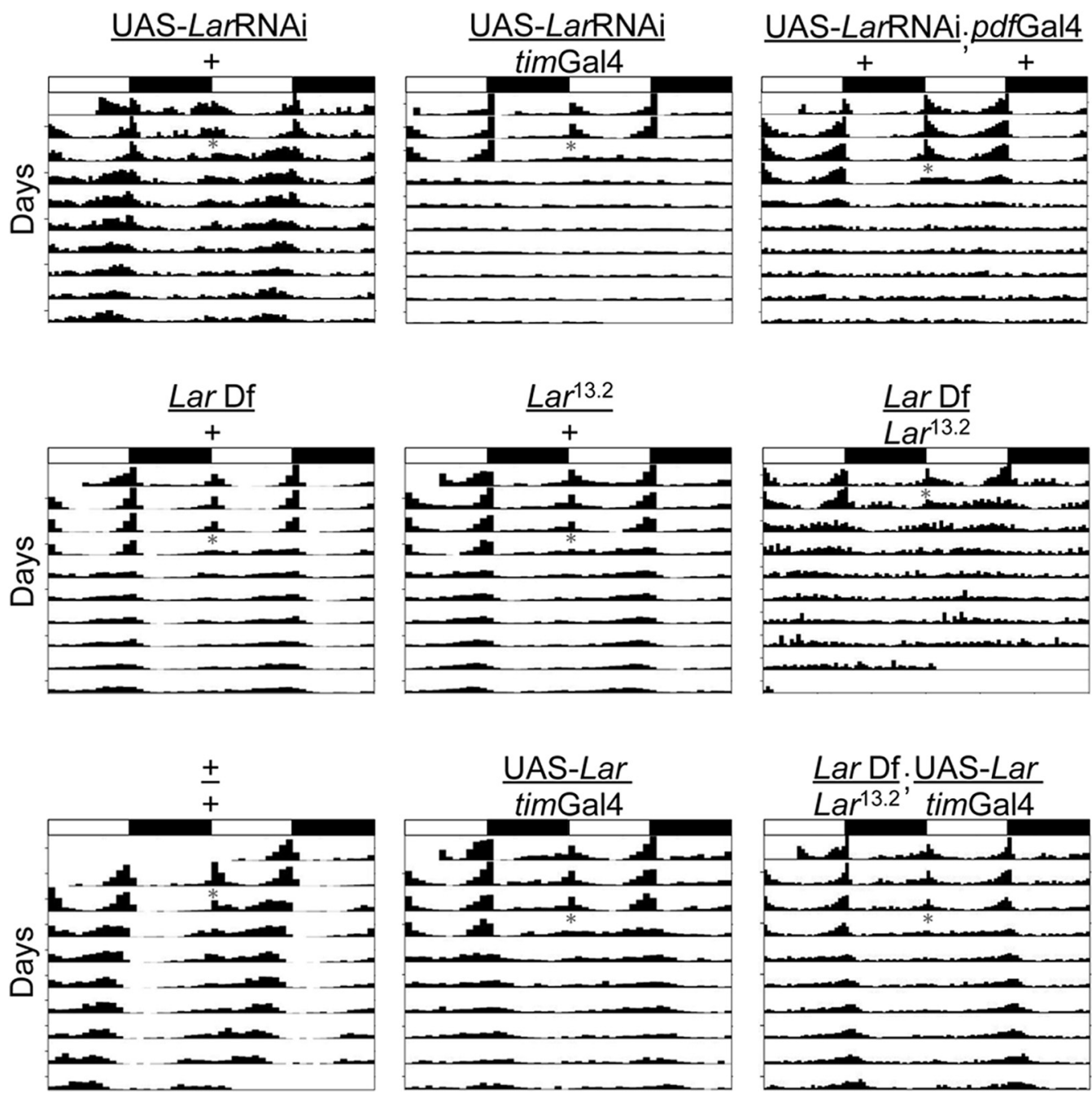

Figure 1. Locomotor activity analysis of clock-cell-specific Lar RNAi knockdown and Lar mutant flies. Adult males of the indicated genotypes were entrained in LD for $3 \mathrm{~d}$ and transferred to DD (gray asterisk) for at least $7 \mathrm{~d}$. Analysis of activity in DD and fly genotypes are as described in Materials and Methods. Representative double-plotted actograms for single flies of each genotype are shown. White boxes, lights-on period; black boxes, lights-off period; vertical bars, fly activity. The height of vertical bars indicates relative level of activity.

Table 2. Lar expression in clock cells rescues activity rhythms in Lar mutant and RNAi knockdown flies

\begin{tabular}{|c|c|c|c|c|}
\hline Genotype & Total & Rhythmic, \% & Period \pm SEM & Strength \pm SEM \\
\hline$w^{1118} ;+;$ UAS-Lar $/+$ & 14 & 100 & $23.57 \pm 0.04$ & $92.86 \pm 9.91$ \\
\hline$w^{1118} ;+;$;imGal4/+ & 15 & 93 & $23.58 \pm 0.06$ & $58.54 \pm 4.63$ \\
\hline$w^{1118 ;} ;+$ UAS-Lar/timGal4 & 16 & 88 & $24.20 \pm 0.32$ & $65.16 \pm 5.98^{\dagger}$ \\
\hline $\begin{array}{l}\text { w }^{1118} ; \text { Lar Df/Lar } \\
\text { timGal4 }\end{array}$ & 14 & 86 & $24.67 \pm 0.10$ & $26.70 \pm 7.05^{*}$ \\
\hline $\begin{array}{l}w^{1118} ; \text { UAS-Dicer2/+;UAS-Lar/ } \\
\quad \text { timGal4 }\end{array}$ & 15 & 80 & $24.21 \pm 0.22$ & $29.95 \pm 8.61$ \\
\hline $\begin{array}{l}w^{1118} ; \text { UAS-Dicer2/UAS-LarRNAi; } \\
\text { UAS-Lar/timGal4 }\end{array}$ & 16 & 88 & $24.54 \pm 0.24$ & $14.61 \pm 1.14^{\#}$ \\
\hline
\end{tabular}

Adult flies were entrained in LD for $3 \mathrm{~d}$ and transferred to $\mathrm{DD}$ for at least $7 \mathrm{~d}$. Analysis of activity rhythms in $\mathrm{DD}$ and fly genotypes are as described in Materials and Methods. The Total, Rhythmic \%, Period \pm SEM, and Power \pm SEM columns are as described in Table 1.

*Rhythm strength is significantly different $(p<0.004)$ than $w^{1118} ;$ Lar $13.2 /+;+$ and $w^{1118} ;$ Lar Df $/+;+$ flies (Table 1).

"Rhythm strength is significantly different ( $p=0.02$ ) than UAS-Dicer2;UAS-LarRNAi/timGal4; +flies (Table 1). ${ }^{+}$Rhythm strength is significantly different $(p=0.011)$ than $w^{1118 ;} ;+;$ UAS-Larl + , but not significantly different $(p=0.39)$ than $w^{1118 ;} ;+;$ timGal $4 /+$.

were calculated to generate histograms. The times of morning and evening activity peaks (phase values) were computed using ClockLab. Morning Anticipation Index values were calculated as the ratio of activity counts occurring $3 \mathrm{~h}$ before lights-on over activity counts occurring $6 \mathrm{~h}$ before lights-on as described previously (Harrisingh et al., 2007; De et al., 2013). All $p$ values were calculated using a Student's two-tailed $t$ test with unequal variance.

Immunohistochemistry. Antibody staining of larval CNSs and adult fly brains was performed as previously described (Houl et al., 2008). Briefly, larval CNSs and adult brains were dissected in $1 \times$ PBS and fixed with $3.7 \%$ formaldehyde in $1 \times$ PBS at room temperature (RT) for $15 \mathrm{~min}$. Samples were then washed and incubated with blocking solution containing $1 \times$ PBS, $5 \%$ BSA, $5 \%$ goat serum ( $5 \%$ donkey serum for primary antibodies raised in goat), $0.03 \%$ sodium deoxycholate, and $0.03 \%$ TritonX100 at RT for $1 \mathrm{~h}$ followed by incubation with primary antibodies overnight $(\mathrm{ON})$ at $4^{\circ} \mathrm{C}$ in blocking solution. Primary antibodies and their dilutions used were as follows: guinea pig anti-CLK GP50 1:3000 (Houl et al., 2008), goat anti-CLK dC-17 (Santa Cruz Biotechnology) 1:100, rabbit anti-GFP ab6556 (Abcam) 1:500, pre-absorbed rabbit anti-PER (gift from Michael Rosbash, Brandeis University, Waltham, MA) 1:15,000, and mouse anti-PDF (Developmental Studies Hybridoma Bank) 1:500. For detection of primary antisera, the following secondary antibodies were used at a dilution of 1:200 (incubated $\mathrm{ON}$ at $4^{\circ} \mathrm{C}$ ) in blocking solution: goat anti-rabbit AlexaFluor 488 (Invitrogen), donkey antirabbit AlexaFluor 647 (Invitrogen), goat anti-guinea pig Cy-3 (Jackson ImmunoResearch Laboratories), donkey anti-guinea pig AlexaFluor 488 (Invitrogen), goat anti-mouse AlexaFluor 488 and AlexaFluor 647 (Invitrogen), and donkey anti-goat AlexaFluor 488 (Invitrogen). Brains were then mounted in Vectashield mounting medium (Vector Labora- 
A

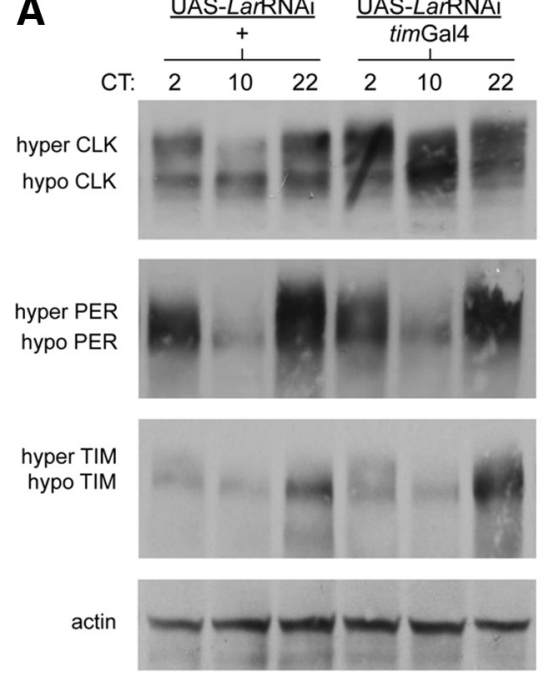

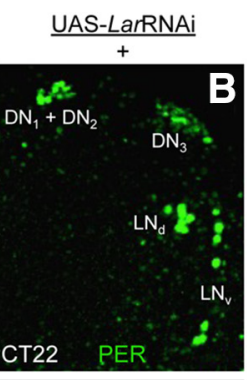

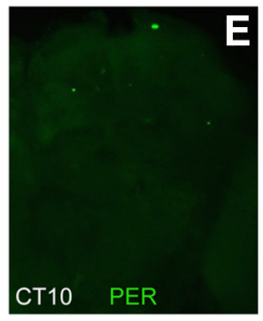

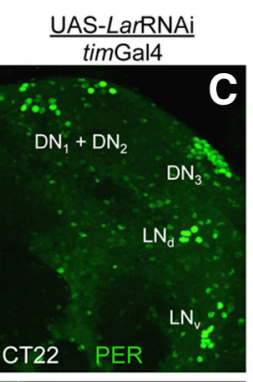
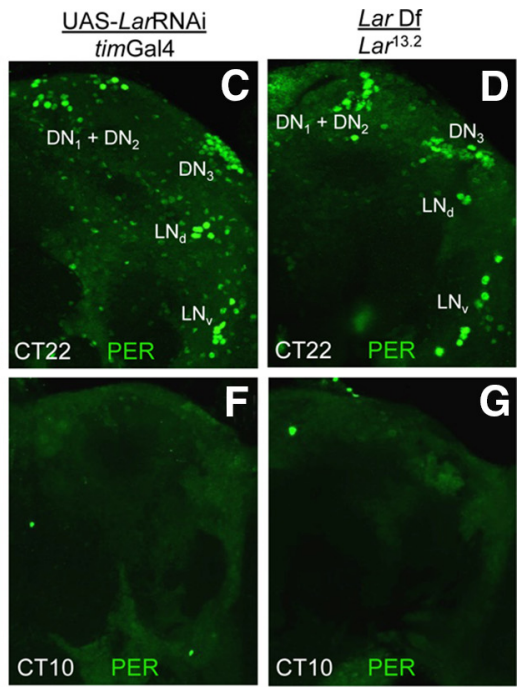

Figure 2. Rhythms in clock gene expression are intact in Lar knockdown flies. Flies were entrained for $3 \mathrm{~d}$ in LD conditions and collected at the indicated times on the first day of DD for Western analysis or the third day of DD for PER immunostaining. $A$, Western blots of head extracts from $w^{1718} ;$ UAS-LarRNAi/ + and UAS-Dicer2/+;UAS-LarRNAi/timGal4 (UAS-LarRNAi/timGal4) flies were probed with CLK, PER, and TIM antisera. Bands corresponding to hyperphosphorylated CLK, PER, and TIM (hyperCLK, hyperPER, and hyperTIM, respectively) and hypophosphorylated CLK, PER, and TIM (hypoCLK, hypoPER, hypoTIM, respectively) are shown. Actin serves as a loading control. $\boldsymbol{B}-\boldsymbol{G}$, Brains dissected from adult flies collected at CT22 or CT10 were immunostained with PER antisera and imaged by confocal microscopy. $\boldsymbol{B}, \boldsymbol{E}$, Projected Z-series images of right brain hemispheres from $w^{1118} ;$ UAS-LarRNAi/ + flies. $\boldsymbol{C}, \boldsymbol{F}$, Projected Z-series images of right brain hemispheres from UAS-Dicer2/+;UAS-LarRNAi/timGal4 (UAS-LarRNAi/timGal4) flies. D, G, Projected Z-series images of right brain hemispheres from Df(2L)E55/Lar ${ }^{13.2}$ (Lar Df/Lar ${ }^{13.2}$ ) flies. PER staining is detected in all three groups of dorsal neurons $\left(\mathrm{DN}_{1}+\mathrm{DN}_{2}, \mathrm{DN}_{3}\right) ; \mathrm{LN}_{\mathrm{d}}$; and $\mathrm{LN}_{\mathrm{v}}$. All images are representative of nine or more fly brains.

tories) for imaging. Entrained L3 larvae or 1- to 5-d-old adults were used for dissection.

Imaging. Larval CNSs and adult fly brains were imaged using an Olympus FV1000 confocal microscope (Olympus America) as described previously (Liu et al., 2015). Briefly, serial optical scans were obtained at 2 $\mu \mathrm{m}$ intervals without using Kalman-averaging. For coimmunostaining experiments, sequential scans of the Argon $488 \mathrm{~nm}$ and $\mathrm{HeNe}(543 \mathrm{~nm}$ for Cy3, $633 \mathrm{~nm}$ for AlexaFluor 647 and Cy5) lasers were used to avoid bleed-through between channels. For imaging AlexaFluor 488 and Cy3; Argon $488 \mathrm{~nm}$ and HeNe $543 \mathrm{~nm}$ lasers were used, with the 405/488/543 $\mathrm{nm}$ dichronic mirror for excitation whereas for imaging AlexaFluor 488 and either AlexaFluor 647 or Cy5; Argon $488 \mathrm{~nm}$ and HeNe $633 \mathrm{~nm}$ lasers were used, with the 488/543/633 nm dichronic mirror for excitation. Fluorescence signals were separated by a beam splitter (560-nm-long pass) and recorded on spectral detectors set to $500-530 \mathrm{~nm}$ for AlexaFluor 488, 555-655 nm for Cy3, and a detector with 650-nm-long pass filter for AlexaFluor 647 or Cy5. The Fluoview "Hi-Lo" lookup table was used to set the maximal signal below saturation and set the background to near zero using the high voltage and offset controls. Original Olympus images were saved as 12 bit oib format and processed using FV1000 confocal software to generate Z-stack series. Images were adjusted for brightness and contrast using FV1000 confocal software when needed. For each genotype and developmental stage, brain images were acquired using the same settings (power, gain, offset) at the same time.

Western blot analysis. For preparing protein extract from adult fly heads, flies were entrained in LD cycles for at least $3 \mathrm{~d}$ and collected at circadian time (CT)2, CT10, and CT22 on day 1 of constant darkness. Lysis was performed in radioimmunoprecipitation assay buffer $(20 \mathrm{mM}$ Tris, pH 7.5, 150 mм NaCl, 1 mм EDTA, 0.05 mм EGTA, 10\% glycerol, $1 \%$ Triton X-100, $0.4 \%$ sodium deoxycholate, $0.1 \%$ SDS) containing protease inhibitor mixture $(0.5 \mathrm{~mm}$ phenylmethylsulfonyl fluoride, 10 $\mu \mathrm{g} / \mathrm{ml}$ aprotinin, $10 \mu \mathrm{g} / \mathrm{ml}$ leupeptin, $2 \mu \mathrm{g} / \mathrm{ml}$ pepstatin A, $1 \mathrm{~mm}$ $\mathrm{Na}_{3} \mathrm{VO}_{4}$, and $1 \mathrm{~mm} \mathrm{NaF}$ ). This homogenate was sonicated five to eight times for $10 \mathrm{~s}$ each, using a Microson ultrasonic cell disruptor at a setting of $4-5$, and then centrifuged at $20,000 \times g$ for $10 \mathrm{~min}$. The supernatant was collected and protein concentration was determined by the Coomassie-based Bradford Assay. Three hundred nanograms of total protein for each genotype were loaded in each lane. Soluble protein extracts were separated on $5 \%$ polyacrylamide electrophoresis gels, transferred to supported nitrocellulose membranes (MSI) and incubated with GP50 anti-CLK (1:4000), pre-absorbed rabbit anti-PER (1:65,000, gift from Michael Rosbash), rat anti-TIM (1:1000, gift from Amita Sehgal, University of Pennsylvania, Philadelphia, PA), or anti- $\beta$-ACTIN (1: 5000; Sigma-Aldrich) antibodies. Goat anti-rabbit, anti-guinea-pig, antirat, and anti-mouse conjugated to horseradish peroxidase were used at a 1:2000 dilution (Jackson Immunoresearch) as secondary antibodies. Chemiluminescent detection was used to develop the reaction using ECL plus (GE Healthcare) reagent.

\section{Results}

Reducing LAR expression in clock cells abolishes activity rhythms

In Drosophila, release of transcriptional repression by the degradation of PER and TIM proteins occurs simultaneously with the replacement of hyperphosphorylated CLK by transcriptionally competent hypophosphorylated CLK (Yu et al., 2006). Likewise, multiple kinases and phosphatases control the phosphorylation state of PER and TIM, which determines the timing of transcriptional repression by regulating their nuclear localization and stability (Hardin, 2011). We sought to identify phosphatases that promote CLK-CYC transcriptional activation upon dephosphorylation of core clock components. The loss of such phosphatases is predicted to delay CLK-CYC transcriptional activity, slow PER-TIM degradation, and/or their nuclear localization; all of which act to lengthen circadian period (Sathyanarayanan et al., 2004; Fang et al., 2007; Andreazza et al., 2015).

To identify phosphatases that dephosphorylate clock proteins, we used clock-cell-specific RNAi knockdown to screen a total of $\sim 100$ protein phosphatases for altered locomotor activity rhythms. The timGal4 and $p d f G a l 4$ drivers were used to express UAS-phosphatase RNAi in either all clock cells or in PDFpositive $\mathrm{LN}_{\mathrm{v}} \mathrm{s}$ alone. The screen identified 22 genes that either lengthened or shortened circadian period by $\geq 1 \mathrm{~h}$ ( $p \leq 0.05$ compared with controls) or were arrhythmic. An RNAi line targeting the RPTP Lar (UAS-LarRNAi) was largely arrhythmic when driven by either tim Gal4 or pdfGal4 during DD, whereas tim Gal4, pdfGal4 and UAS-LarRNAi controls showed high levels 
of rhythmicity (Table 1; Fig. 1). When UAS-Dicer2 was used to enhance the RNAi potency (Dietzl et al., 2007), flies expressing Lar RNAi in all clock cells or PDF-positive $\mathrm{LN}_{\mathrm{v}} \mathrm{s}$ were almost entirely arrhythmic (Table 1). Whether or not $\mathrm{Di}$ cer2 was used to enhance Lar RNAi potency, knocking down Lar expression in clock cells caused a significant $(p<0.01)$ increase in arrhythmicity.

To independently confirm that decreased Lar expression abolishes activity rhythms, we tested loss of function Lar mutants for behavioral defects. Lar-null mutants, although capable of completing embryogenesis and early larval development, die as late third instar larvae or pupae (Krueger et al., 1996). Because homozygous Lar-null mutants do not survive to adulthood, we tested transheterozygous combinations of isogenized Lar loss-of-function alleles for locomotor activity rhythms. One allelic combination, Lar deficiency Df(2L)E55 over point mutant $\operatorname{Lar}^{13.2}$ (Lar Df/Lar ${ }^{13.2}$ ), was viable, even though both alleles are predicted to be null for LAR function (Krueger et al., 1996). Activity rhythms in Lar Df/Lar ${ }^{13.2}$ flies were abolished, as reflected by a significant $(p<0.001)$ decrease in rhythm strength compared with Lar Df/+ and $\operatorname{Lar}^{13.2} /+$ flies (Table 1; Fig. 1), thus confirming the behavioral phenotype and the specificity of Lar RNAi.

Because reduced levels of Lar in clockcell-specific Lar RNAi knockdown and Lar Df/Lar ${ }^{13.2}$ flies caused high levels of arrhythmicity, we reasoned that expressing Lar specifically in clock cells would rescue the arrhythmic phenotype associated with these genotypes. To express Lar in clock cells, tim Gal4 was used to drive UAS-Lar. When timGal4 was used to express UAS-Lar in clock-cell-specific Lar RNAi knockdown or Lar Df/Lar ${ }^{13.2}$ mutant flies, rhythmic activity was restored (Table 2; Fig. 1), consistent with the significant increase in rhythm strength compared with control timGal4 driven Lar RNAi $(p=0.0032)$ and Lar Df/Lar ${ }^{13.2}(p=0.02)$ flies (Table 1$)$. Rescue of clock-cell-specific Lar RNAi knockdown and Lar Df/ Lar $^{13.2}$ arrhythmicity by clock-cell-specific Lar expression further demonstrates that LAR levels and/or activity are required for rhythmic activity.

\section{Molecular clock gene oscillations are preserved in Lar knockdown flies}

Because Lar is an RPTP, we expected that reducing LAR levels would result in increased clock protein phosphorylation, thus disrupting feedback loop progression and/or function. To determine whether reducing Lar expression alters PER, TIM and/or CLK phosphorylation or abundance, antibodies against these proteins were used to probe Western blots containing head extracts from timGal4 driven UAS-LarRNAi and UAS-LarRNAi flies without a Gal4 driver collected at different Zeitgeber times (ZTs; where ZT0 is lights-on and ZT12 is lights-off) during LD cycles or different CTs (where CT0 is subjective lights-on and CT12 is subjective lights-off) during DD. CT2, CT10, and CT22 time points were selected to detect differences in abundance and/or phosphorylation because higher levels and/or hyperphosphorylated forms of clock proteins are present at CT22 and CT2 and lower levels and/or hypophosphorylated forms of clock proteins are present at CT10. Neither CLK, PER, and TIM phosphorylation, as measured by the lower mobility forms, nor abundance were noticeably different in head extracts from timGal4 driven UAS-LarRNAi and control UAS-Lar$\mathrm{RNAi} /+$ flies during LD (data not shown) or DD conditions (Fig. $2 A$ ). This result demonstrates that the molecular oscillator in clockcell-specific Lar RNAi knockdown flies is functioning similar to that in controls having normal Lar levels, at least in fly heads, where $>90 \%$ clock protein signal comes from photoreceptor expression (Glossop and Hardin, 2002). 

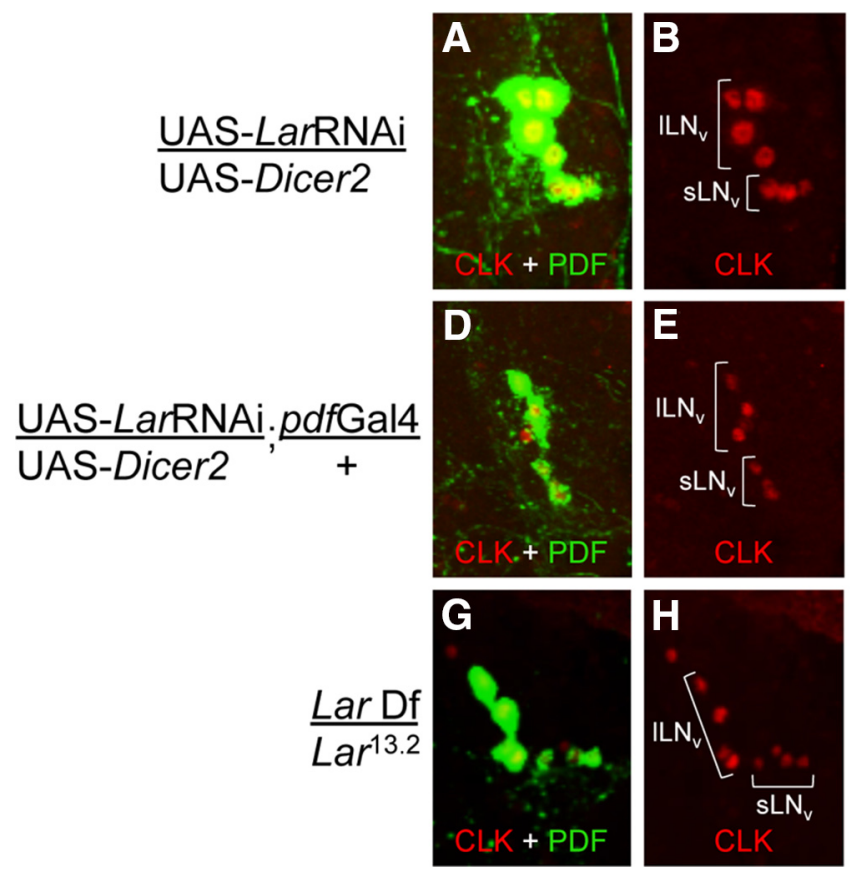

Figure 4. Both $I L N_{v} s$ and $s L N_{v} s$ are present in PDF neuron-specific Lar RNAi knock down and Lar Df/Lar ${ }^{13.2}$ mutant flies. Brains dissected from adult flies collected at ZT2 were immunostained with CLK and PDF antibodies and the region containing $L_{v} s$ was imaged by confocal microscopy. $\boldsymbol{A}$-C, Projected Z-series $(18 \mu \mathrm{m})$ from a UAS-LarRNAi/UAS-Dicer 2 brain. $\boldsymbol{D}-\boldsymbol{F}$, Twelve micrometer projected Z-series image from a UAS-LarRNAi/UAS-Dicer2;pdfGal4/+ brain. G-I, Fourteen micrometer projected Z-series image from a $L a r$ Df $/$ Lar $^{13.2}$ brain. Colocalization of PDF (green) and CLK (red) is seen as yellow. All images are representative of eight or more fly brains.

To directly assess clock protein localization and cycling in pacemaker neurons in clock-cell-specific Lar RNAi knockdown and Lar Df/Lar ${ }^{13.2}$ flies, PER distribution was monitored in dissected brains during LD (data not shown) and DD. Newly eclosed UAS-LarRNAi/+, timGal4 driven UAS-LarRNAi and Lar Df/ Lar $^{13.2}$ adults were synchronized in LD and collected for dissection at the predicted PER peak (CT22) and trough (CT10) time points on the third day after transfer to DD. Remarkably, PER expression in timGal4 driven UAS-LarRNAi and Lar Df/Lar ${ }^{13.2}$ brains was indistinguishable from UAS-LarRNAi/+ controls at both peak and trough time points during LD (data not shown) and DD (Fig. $2 B-G$ ). In each of these genotypes, PER was readily detected in all pacemaker neuron groups at CT22 (Fig. $2 B-D$ ), but was undetectable at CT10 (Fig. 2E-G). Cycling of PER protein in whole heads from timGal4 driven UAS-LarRNAi flies and pacemaker neurons from timGal4 driven UAS-LarRNAi and Lar Df/ Lar $^{13.2}$ flies demonstrates that Lar does not disrupt molecular oscillator function. These results suggest that Lar functions downstream of the molecular oscillator to disrupt activity rhythms.

\section{PDF accumulation is impaired in Lar knockdown flies}

A key regulator of locomotor activity rhythms is the neuropeptide PDF (Renn et al., 1999), which rhythmically accumulates in the $\mathrm{SLN}_{\mathrm{v}}$ projections into the dorsal brain (hereafter $\mathrm{SLN}_{\mathrm{v}}$ dorsal projections) with a peak early in the day (Park et al., 2000). To determine whether defects in PDF expression give rise to the arrhythmic activity seen in clock-cell-specific Lar RNAi knockdown and Lar Df/Lar ${ }^{13.2}$ mutant flies, PDF was monitored in brains from PDF neuron-specific Lar RNAi knockdown, Lar Df/ Lar $^{13.2}$ mutant and control flies at ZT2. In $p d f G a l 4$ driven UASLarRNAi flies, PDF immunostaining is markedly reduced or absent (18 of 18 brain hemispheres) in $\mathrm{sLN}_{\mathrm{v}}$ dorsal projections compared with the normal PDF immunostaining (18 of 18 brain
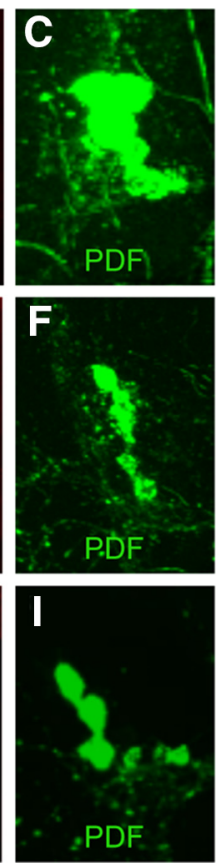

hemispheres) seen in $\mathrm{sLN}_{\mathrm{v}}$ dorsal projections from control UAS-LarRNAi flies (Fig. 3A-F). In contrast, PDF immunostaining in $\mathrm{ILN}_{\mathrm{v}}$ projections to the medulla and accessory medulla (aMe) showed no alterations in $p d f G a l 4$ driven UAS-LarRNAi or control UAS-LarRNAi flies (18 of 18 brain hemispheres for each genotype; Fig. $3 A-F)$, whereas PDF immunstaining in $\mathrm{ILN}_{\mathrm{v}}$ projections to the posterior optic tract (POT) were absent or disrupted in most $p d f \mathrm{Gal} 4$ driven UASLarRNAi flies (10 of 18 brain hemispheres) but normal in UAS-LarRNAi controls (18 of 18 brain hemispheres) (Fig. 3A-F). Likewise, wild-type PDF immunostaining was detected in $\mathrm{sLN}_{\mathrm{v}}$ dorsal projections from Lar Df/ + and Lar $^{13.2} /+$ control flies (16 of 16 brain hemispheres for each genotype), but PDF immunostaining was absent in $\mathrm{sLN}_{\mathrm{v}}$ dorsal projections in Lar Df/Lar ${ }^{13.2}$ mutants (16 of 16 brain hemispheres; Fig. 3G-O). PDF expression in $\operatorname{lLN}_{\mathrm{v}}$ projections to the medulla and aMe were present but appeared less intense in $\operatorname{Lar} \mathrm{Df} / \operatorname{Lar}^{13.2}$ mutants than in control Lar Df/+ and $\operatorname{Lar}^{13.2} /+$ flies (16 of 16 brain hemispheres), and PDF levels in the POT projection were drastically reduced or absent in Lar Df/Lar ${ }^{13.2}$ mutant flies ( 8 of 16 brain hemispheres) compared with Lar Df/+ and Lar $^{13.2} /+$ controls (Fig. 3G-O).

If the lack of PDF accumulation in $\mathrm{SLN}_{\mathrm{v}}$ dorsal projections is due to decreased Lar levels, then expressing Lar in clock cells should restore PDF expression in these projections. Indeed, when tim Gal4 was used to drive UAS-Lar in Lar Df/Lar ${ }^{13.2}$ flies, wildtype PDF immunostaining was detected in $\mathrm{sLN}_{\mathrm{v}}$ dorsal projections and $\mathrm{lLN}_{\mathrm{v}}$ medulla projections (16 of 16 brain hemispheres; Fig. $3 P-R$ ). However, PDF expression in $\mathrm{ILN}_{\mathrm{v}}$ POT projections was not completely restored by expressing Lar in all clock neurons ( 8 of 16 brain hemispheres were disrupted or absent; Fig. $3 P-R$ ). The lack of PDF accumulation in $\mathrm{sLN}_{\mathrm{v}}$ dorsal projections is not due to the loss of $s \mathrm{NN}_{\mathrm{v}} \mathrm{s}$ in flies with impaired Lar expression; CLK is expressed in $\mathrm{sLN}_{\mathrm{v}}$ nuclei of $p d f \mathrm{Gal} 4$ driven UASLarRNAi flies, Lar Df/Lar ${ }^{13.2}$ mutants and control flies with varying levels of PDF (Fig. 4). CLK levels in pdfGal4 driven UASLarRNAi and Lar Df/Lar ${ }^{13.2}$ mutant flies were not significantly different $(p>0.05)$ than the UAS-LarRNAi and Lar Df/ + or $\operatorname{Lar}^{13.2} /+$ controls, respectively. These data demonstrate that LAR expression in PDF neurons is required for PDF accumulation in $\mathrm{SLN}_{\mathrm{v}}$ dorsal projections.

Lar is required during development for PDF accumulation in $\mathrm{sLN}_{\mathrm{v}}$ dorsal projections and activity rhythms

Loss of Lar expression in pacemaker neurons could abolish activity rhythms and PDF accumulation in $\mathrm{SLN}_{\mathrm{v}}$ dorsal projections by blocking clock output pathway development, maintenance, or both. To determine whether LAR is required in adults for locomotor activity rhythms, Lar RNAi was expressed in PDFexpressing neurons post-eclosion using the Gal80 ${ }^{\text {ts }}$ TARGET system (McGuire et al., 2003). In flies raised and tested at the permissive temperature $\left(18^{\circ} \mathrm{C}\right), \mathrm{Gal} 80^{\text {ts }}$ inhibits $p d f \mathrm{Gal} 4$ driven UAS-LarRNAi, resulting in rhythms with a period of $23.54 \mathrm{~h}$ 
Table 3. PDF neuron-specific Lar RNAi knockdown during development, but not in adults, abolishes activity rhythms

\begin{tabular}{|c|c|c|c|c|}
\hline Genotype (temperature raised $\gg$ temperature tested) & Total & Rhythmic, \% & Period \pm SEM & Strength \pm SEM \\
\hline$w^{1118} ;+;+\left(18^{\circ} \mathrm{C} \gg 30^{\circ} \mathrm{C}\right)$ & 16 & 94 & $23.50 \pm 0.12$ & $29.35 \pm 12.45$ \\
\hline$w^{1118} ;$ tub-Gal $80^{\text {ts }} /+; p d f G a \mid 4 /+\left(18^{\circ} \mathrm{C} \gg 30^{\circ} \mathrm{C}\right)$ & 18 & 89 & $23.94 \pm 0.13$ & $14.05 \pm 2.55$ \\
\hline$w^{1118} ;$ UAS-LarRNAi $/+;+\left(18^{\circ} \mathrm{C} \gg 30^{\circ} \mathrm{C}\right)$ & 15 & 100 & $23.59 \pm 0.08$ & $21.41 \pm 4.46$ \\
\hline$w^{1118} ;$ UAS-LarRNAi/tub-Gal80 $0^{\text {ts }} ;$ pdfGal4/+ $\left(18^{\circ} \mathrm{C} \gg 30^{\circ} \mathrm{C}\right)$ & 18 & 94 & $23.46 \pm 0.21$ & $17.62 \pm 3.05$ \\
\hline$w^{1118} ;+;+\left(30^{\circ} \mathrm{C} \gg 30^{\circ} \mathrm{C}\right)$ & 12 & 92 & $24.41 \pm 0.11$ & $17.48 \pm 2.01$ \\
\hline$w^{1118} ;$ tub-Gal $80^{\text {ts }} /+; p d f G a \mid 4 /+\left(30^{\circ} \mathrm{C} \gg 30^{\circ} \mathrm{C}\right)$ & 15 & 87 & $24.04 \pm 0.13$ & $31.75 \pm 10.01$ \\
\hline$w^{1118} ;$ UAS-LarRNAi $/+;+\left(30^{\circ} \mathrm{C} \gg 30^{\circ} \mathrm{C}\right)$ & 14 & 93 & $23.61 \pm 0.14$ & $16.21 \pm 1.8$ \\
\hline$w^{1118} ;$ UAS-LarRNAi/tub-Gal80 $0^{\text {ts }} ; p d f G a 14 /+\left(30^{\circ} \mathrm{C} \gg 30^{\circ} \mathrm{C}\right)$ & 18 & 6 & 24.50 & $3.44 \pm 1.17^{*}$ \\
\hline$w^{1118} ;+;+\left(18^{\circ} \mathrm{C} \gg 18^{\circ} \mathrm{C}\right)$ & 12 & 83 & $23.45 \pm 0.05$ & $35.13 \pm 9.46$ \\
\hline$w^{1118} ;$ tub-Gal $80^{\text {ts }} /+;$ pdfGal $4 /+\left(18^{\circ} \mathrm{C} \gg 18^{\circ} \mathrm{C}\right)$ & 12 & 83 & $23.30 \pm 0.08$ & $43.76 \pm 7.94$ \\
\hline$w^{1118} ;$ UAS-LarRNAi $/+;\left(18^{\circ} \mathrm{C} \gg 18^{\circ} \mathrm{C}\right)$ & 16 & 88 & $23.50 \pm 0.10$ & $15.01 \pm 1.34$ \\
\hline$w^{1118} ;$ UAS-LarRNAi/tub-Gal80 ${ }^{\text {ts }} ; p d f G a \mid 4 /+\left(18^{\circ} \mathrm{C} \gg 18^{\circ} \mathrm{C}\right)$ & 17 & 88 & $23.61 \pm 0.09$ & $47.37 \pm 6.31$ \\
\hline$w^{1118} ;+;+\left(30^{\circ} \mathrm{C} \gg 18^{\circ} \mathrm{C}\right)$ & 12 & 92 & $23.43 \pm 0.03$ & $27.79 \pm 6.23$ \\
\hline$w^{1118} ;$ tub-Gal $80^{\text {ts }} /+; p d f G a l 4 /+\left(30^{\circ} \mathrm{C} \gg 18^{\circ} \mathrm{C}\right)$ & 15 & 80 & $23.71 \pm 0.16$ & $30.67 \pm 18.72$ \\
\hline$w^{1118} ;$ UAS-LarRNAi $/+;+\left(30^{\circ} \mathrm{C} \gg 18^{\circ} \mathrm{C}\right)$ & 12 & 83 & $23.56 \pm 0.07$ & $13.48 \pm 2.06$ \\
\hline$w^{1118} ;$ UAS-LarRNAi/tub-Gal80 $0^{\text {ts }} ;$ pdfGal $4 /+\left(30^{\circ} \mathrm{C} \gg 18^{\circ} \mathrm{C}\right)$ & 15 & 13 & $24.75 \pm 0.11$ & $6.85 \pm 1.47^{*}$ \\
\hline
\end{tabular}

Adult males of the indicated genotypes were either raised (first temperature in parenthesis) at the permissive temperature $\left(18^{\circ} \mathrm{C}\right)$ to block Gal4-dependent expression of Lar RNAi or the restrictive temperature $\left(30^{\circ} \mathrm{C}\right)$ to permit Gal4-dependent expression of Lar RNAi. After eclosion, adult flies of the indicated genotype were entrained for $3 \mathrm{~d}$ in LD and monitored for seven days in constant darkness (second temperature in parenthesis) at either $18^{\circ} \mathrm{C}$ or $30^{\circ} \mathrm{C}$. Flies raised and $/$ or tested at $30^{\circ} \mathrm{C}$ showed a $30-50 \%$ lower survival rate. Analysis of activity in DD and fly genotypes are as described in Materials and Methods. The Total, Rhythmic \%, Period \pm SEM, and Power \pm SEM columns are as described in Table 1.

*Significantly different $(p<0.05)$ rhythm strength compared to controls exposed to the same temperature regime. Lar RNAi knockdown flies raised at $18^{\circ} \mathrm{C}$ and tested at $30^{\circ} \mathrm{C}$ were not significantly different ( $\left.p>0.29\right)$ than controls exposed to this temperature regime. Lar RNAi knockdown flies raised and tested at $18^{\circ} \mathrm{C}$ were not significantly different $(p>0.28)$ than all controls exposed to this temperature regime except for UAS-Lar RNAi flies, which had significantly $(p<0.01)$ weaker rhythms.

(Table 3, row 12), and strengths that were either not different $(p>0.28)$ or stronger $(p<0.02)$ than controls unable to express Lar RNAi (Table 3, rows 9-11). When pdfGal4 driven UAS-LarRNAi flies were raised at $18^{\circ} \mathrm{C}$ and transferred to restrictive temperature $\left(30^{\circ} \mathrm{C}\right)$ after eclosion, Lar RNAi is only expressed in PDF neurons of adults. However, these flies were just as rhythmic $(p>0.29)$ as control flies that are unable to express Lar RNAi after eclosion and had comparable periods (Table 3, compare row 4 to rows 1-3). These results suggest that LAR expression in PDF neurons after adults emerge is not required for activity rhythms. This result implies that Lar function is required in $\mathrm{sLN}_{\mathrm{v}} \mathrm{s}$ during development since knocking down Lar in PDF neurons during development and in adults essentially eliminates activity rhythms (Table 1 , rows 6 and 10$)$.

To confirm a role for LAR during development, we tested $p d f \mathrm{Gal} 4$ driven UAS-LarRNAi flies for defects in activity rhythms when raised and tested at $30^{\circ} \mathrm{C}$ at the adult stage (continuous Lar knockdown) or raised at $30^{\circ} \mathrm{C}$ and transferred to $18^{\circ} \mathrm{C}$ at the adult stage (development only Lar knockdown). Both continuous and development-only Lar knockdown flies displayed significantly higher arrhythmicity $(p<0.05)$ compared with control strains that showed rhythms with 23.5$24.5 \mathrm{~h}$ circadian periods (Table 3 , compare row 8 to rows $5-7$ and row 16 to rows 13-15). These results confirm that Lar is required during early stages of fly development for rhythms in locomotor activity.
Flies raised at $18^{\circ} \mathrm{C}$ and tested at $30^{\circ} \mathrm{C}$

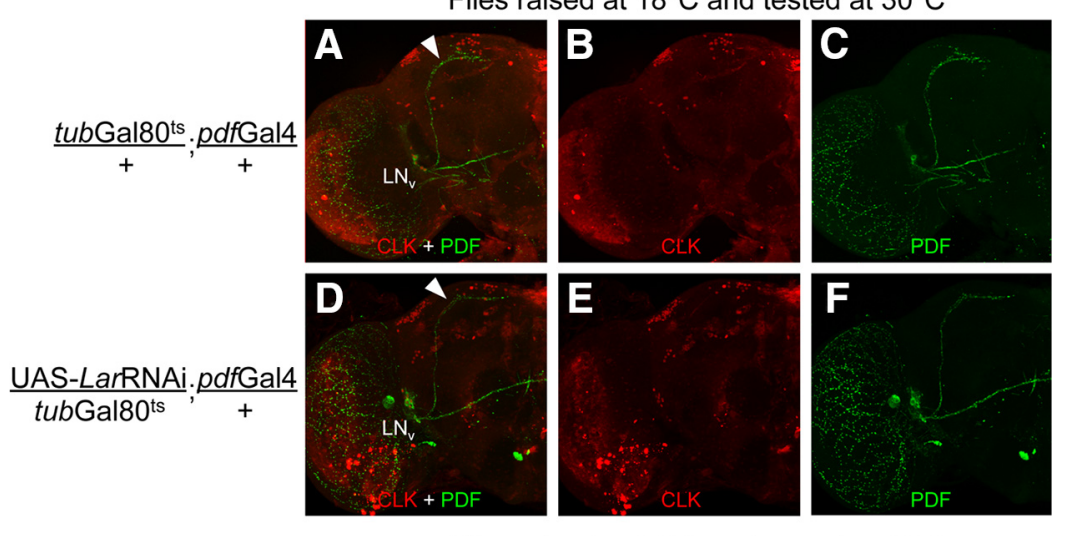

Flies raised at $30^{\circ} \mathrm{C}$ and tested at $18^{\circ} \mathrm{C}$

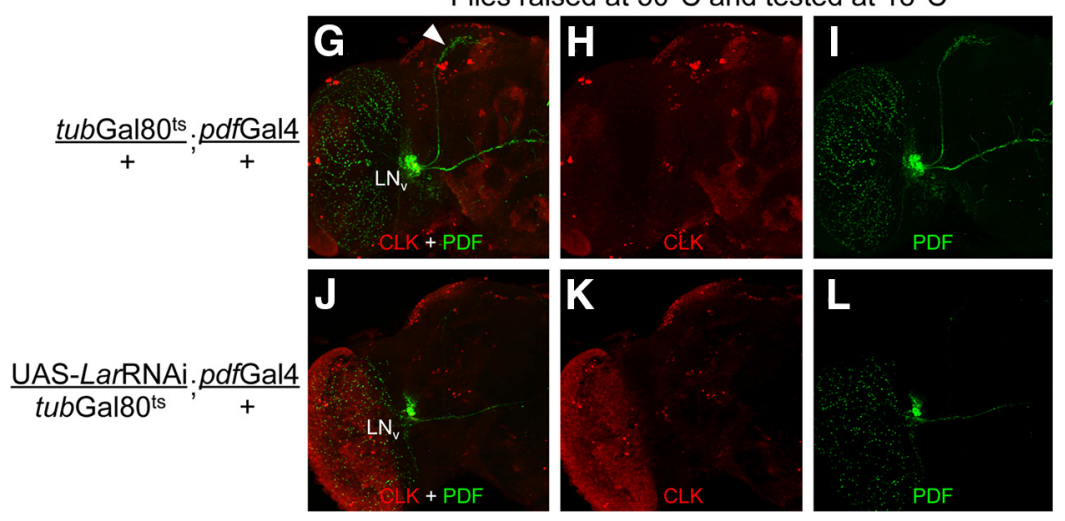

Figure 5. Lar is required during development, but not in adults, for PDF accumulation in $\mathrm{LLN}_{\mathrm{v}}$ dorsal projections. $A-F$, Flies were raised at $18^{\circ} \mathrm{C}$ to block Gal 4 activation, shifted to $30^{\circ} \mathrm{C}$ after eclosion to permit Gal 4 activation, and collected at ZT2. A-C, Seventyfour micrometer projected Z-series image of a tubGal $80^{\text {ts }} /+; p d f G a \mid 4 /+$ brain. $\boldsymbol{D}-\boldsymbol{F}$, Eighty-two micrometer projected Z-series image of a UAS-LarRNAi/tubGal $80^{\text {ts }} ;$ pdfGal $4 /+$ brain. G-L, Flies were raised at $30^{\circ} \mathrm{C}$ to permit Gal 4 activation, shifted to $18^{\circ} \mathrm{C}$ after eclosion to block Gal4 activation, and collected at ZT2. G-I, Eighty-six projected Z-series image of a tubGal80 8 ts + ;pdfGal4/+ brain. $J-L$, Eighty-two micrometer projected Z-series image of a UAS-LarRNAi/tubGal80 ${ }^{\text {ts }} ;$ pdfGal4/+ brain. Brains were dissected, immunostained with CLK and PDF antibodies, and imaged by confocal microscopy. A left brain hemisphere is shown in each image, where lateral is right and dorsal is top. $\mathrm{LN}_{\mathrm{v}}, \mathrm{SLN}_{\mathrm{v}}$, and ILN cell bodies; white arrowhead, $\mathrm{SLN} \mathrm{v}_{\mathrm{v}}$ dorsal projection. All images are representative of 10 or more brain hemispheres. 


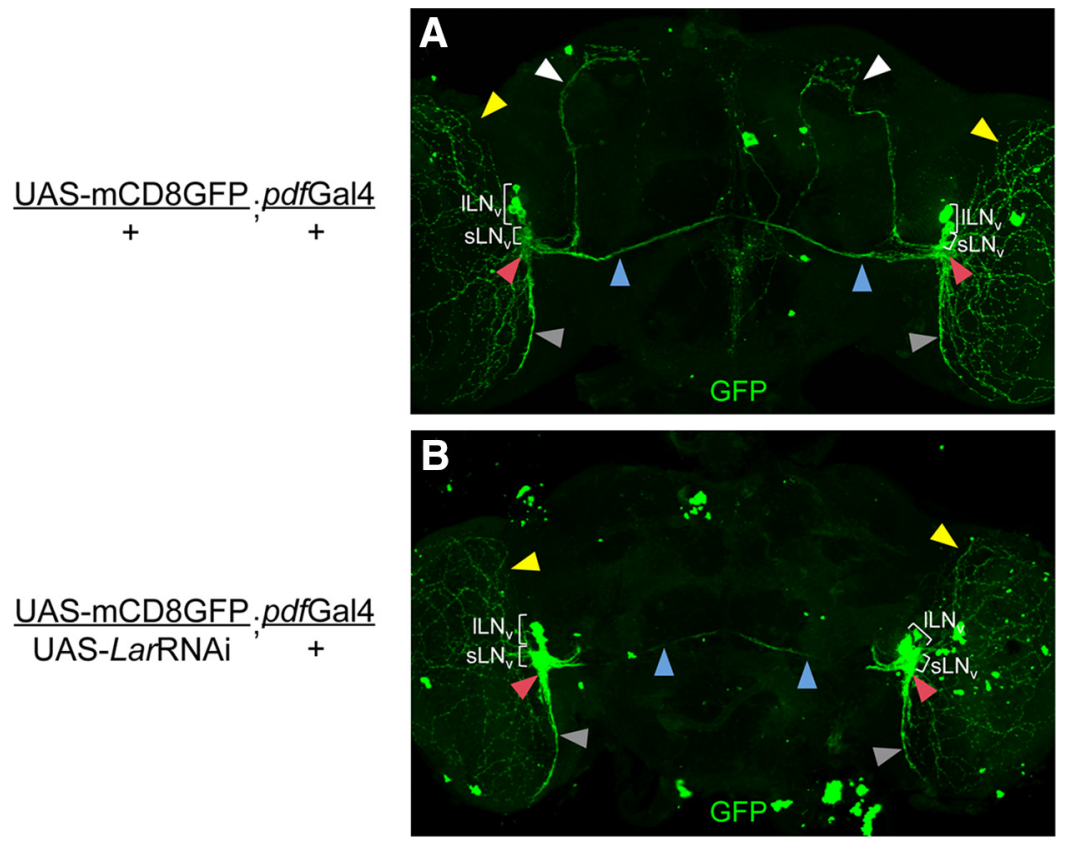

Figure 6. PDF neuron-specific Lar RNAi knockdown eliminates the $S L_{v}$ dorsal projection. Brains were dissected from adult flies collected at ZT2, immunostained with GFP antibody, and imaged by confocal microscopy. Projected Z-series images of whole brains are shown, where lateral is left and dorsal is at the top. $\boldsymbol{A}$, Seventy-six micrometer projected Z-series image from a control UAS-mCD8GFP/+;pdfGal4/+ fly brain. B, Seventy-eight micrometer projected Z-series image from a UAS-mCD8GFP/UAS-LarRNAi;pdfGal4/+ fly brain. White arrowhead, $\mathrm{SLN}_{v}$ dorsal projection; blue arrowhead, ILN $\mathrm{LNOT}_{\mathrm{v}}$ projection; yellow arrowhead, $\operatorname{ILN}_{v}$ medulla projection; red arrowhead, $\mathrm{SLN}_{\mathrm{v}}$ and ILN $\mathrm{v}$ aMe projections; gray arrowhead, ILN $\mathrm{v}_{\mathrm{v}}$ aMe ventral elongation projection. All images are representative of 12 or more brain hemispheres.

Given that the expression of Lar RNAi in PDF neurons after eclosion does not alter rhythmic activity, we expected PDF to accumulate in $\mathrm{sLN}_{\mathrm{v}}$ dorsal projections. Indeed, we observed PDF staining in $\mathrm{SLN}_{\mathrm{v}}$ cell bodies and dorsal projections from flies expressing Lar RNAi in PDF neurons after eclosion that was comparable to controls (Fig. 5A-F). In contrast, flies that express Lar RNAi in PDF neurons during development lacked PDF staining when tested at $18^{\circ} \mathrm{C}$ as adults (Fig. $5 G-L$ ). Together, these results demonstrate that Lar functions during development to permit PDF accumulation in $\mathrm{sLN}_{\mathrm{v}}$ dorsal projections and drive activity rhythms.

\section{Lar disrupts the development of $\mathrm{SLN}_{\mathrm{v}}$ dorsal projections}

During fly development, LAR was previously shown to regulate neuronal morphology, axon guidance and growth in embryos via multiple signaling pathways (eg, BMP, WNT) (Krueger et al., 1996; Desai et al., 1997; Wills et al., 1999; Kaufmann et al., 2002; Berke et al., 2013). Given that Lar plays a role in axonal development, we tested whether $\mathrm{sLN}_{\mathrm{v}}$ dorsal projections were disrupted in PDF neuron-specific Lar RNAi knockdown flies. sLN $_{\mathrm{v}}$ axonal morphology was visualized with a membrane-tethered version of GFP (mCD8-GFP) expressed in PDF-positive neurons. GFP was detected in $\mathrm{sLN}_{\mathrm{v}}$ dorsal projections from control brains at ZT2 (Fig. 6A), when the axonal arbor is at its maximum (Fernández et al., 2008). Strikingly, $\operatorname{sLN}_{\mathrm{v}}$ dorsal projections were either completely absent ( 17 of 18 brain hemispheres) or weakly detected ( 1 of 18 brain hemispheres) in UAS-LarRNAi/UAS-mCD8GFP;pdfGal4/+ adults beyond the dorsomedial defasciculation point (Fig. $6 B)$. Likewise, $\mathrm{lLN}_{\mathrm{v}}$ projections to the medulla and the POT were aberrant ( 8 of 18 brain hemispheres with absent or altered projections) and GFP staining was weak in UAS-LarRNAi/UASmCD8GFP;pdfGal4/+ flies (Fig. 6B). These results show that Lar plays a critical role in the development of $\mathrm{sLN}_{\mathrm{v}}$ dorsal projections (and to a lesser extent in $\mathrm{ILN}_{\mathrm{v}}$ projections), consistent with the loss of PDF accumulation in these processes and loss of behavioral rhythms.

Although Lar mutants and RNAi knockdowns eliminate PDF expression in $\mathrm{sLN}_{\mathrm{v}}$ dorsal projections (Fig. 3), PDF continues to accumulate in $\operatorname{sLN}_{\mathrm{v}}$ and $\mathrm{ILN}_{\mathrm{v}}$ cell bodies and their projections into the medulla, the aMe, and (to a lesser extent) the POT (Figs. 3, 5, 6). The presence of PDF in $\operatorname{sLN}_{v}$ and $\operatorname{lLN}_{v}$ cell bodies and their remaining projections distinguishes Lar mutant and RNAi knockdown flies from the $p d f^{01}$ mutant, which eliminates PDF without altering $\mathrm{sLN}_{\mathrm{v}}$ structure, or PDF neuron ablation flies, which eliminate both PDF and $\mathrm{LN}_{\mathrm{v}} \mathrm{s}$ (Renn et al., 1999). Despite their differences in PDF expression and $\mathrm{sLN}_{\mathrm{v}}$ structure, Lar mutant and RNAi knockdown, $p d f^{01}$ mutant and $\mathrm{LN}_{\mathrm{v}}$ ablation flies all abolish activity rhythms in DD. However, activity rhythms of $p d f^{01}$ mutant and $\mathrm{LN}_{\mathrm{v}}$ ablated flies are also disrupted in diurnal (LD) cycles; the evening activity peak is advanced by $0.5-1 \mathrm{~h}$ and anticipation of lights-on is abolished (Renn et al., 1999). Lar RNAi knockdown flies were therefore tested to determine whether their diurnal activity reflected that of $p d f^{01}$ mutant flies, but surprisingly the phase of their evening activity peak was similar to wild-type controls ( $p \geq 0.07)$ and significantly later $(p<$ $0.001)$ than the $p d f^{01}$ mutant, and they could anticipate lights-on significantly better $(p<0.05)$ than the $p d f^{01}$ mutant (Fig. 7; Table 4). Because PDF expression in $\mathrm{LN}_{\mathrm{v}}$ cell bodies and their projections into the medulla, aMe and POT persist in Lar RNAi knockdown flies, PDF secretion from $\mathrm{LN}_{\mathrm{v}} \mathrm{s}$ could account for the difference in lightdriven activity.

\section{Discussion}

To identify phosphatases that target clock proteins, we performed a clock-cell-specific RNAi screen. In this screen, we found that RNAi knockdown of the RPTP LAR abolishes locomotor activity rhythms (Table 1; Fig. 1). A transheterozygous combination of Lar Df and Lar $^{13.2}$ mutant alleles also displayed arrhythmic activity, thus confirming the RNAi knockdown phenotype. The loss of rhythmicity in clock-cell-specific Lar RNAi knockdown flies and Lar Df/Lar ${ }^{13.2}$ mutants is not due to a defect in core oscillator function; CLK, PER and TIM phosphorylation and abundance were similar in tim Gal4 driven UAS-LarRNAi and control UAS-LarRNAi fly head extracts (Fig. 2A). Likewise, PER oscillations in pacemaker neurons from Lar RNAi knockdown flies were indistinguishable from controls lacking Lar RNAi expression (Fig. 2B). The presence of an intact molecular clock in Lar Df/Lar ${ }^{13.2}$ mutant and clock-cell-specific RNAi knockdown flies suggests that Lar disrupts output from the circadian oscillator.

The loss of activity rhythms in Lar mutant and RNAi knockdown flies is reminiscent of the arrhythmicity seen in $p d f^{01}$ flies during constant darkness (Renn et al., 1999). Mutations that eliminate PDF (or the PDF receptor) are thought to disrupt output signaling from the $\mathrm{sLN}_{\mathrm{v}} \mathrm{s}$ to other tissues and synchronizing cues to different groups of pacemaker neurons, thereby causing arrhythmicity in constant darkness (Renn et al., 1999; Peng et al., 
2003; Lin et al., 2004; Hyun et al., 2005; Lear et al., 2005; Mertens et al., 2005). Given these roles for PDF, we hypothesized that loss of Lar disrupts PDF expression or release. Indeed, PDF neuronspecific Lar RNAi knockdown and Lar Df/ Lar $^{13.2}$ mutants displayed defective PDF staining in $\mathrm{sLN}_{\mathrm{v}}$ dorsal projections, but PDF staining persisted in $\mathrm{LN}_{\mathrm{v}}$ cell bodies and their remaining projections (Figs. 3, 4). These results suggest that the arrhythmic activity seen in PDF neuron-specific Lar RNAi knockdown flies was due to the absence of PDF expression in $\mathrm{SLN}_{\mathrm{v}}$ dorsal projections. Expressing Lar in clock neurons from Lar Df/ Lar $^{13.2}$ mutants rescued PDF expression in $\mathrm{sLN}_{\mathrm{v}}$ dorsal projections and behavioral rhythms (Table 2; Fig. $3 P-R)$, demonstrating that Lar acts in clock cells to mediate PDF release and/or accumulation in $\mathrm{sLN}_{\mathrm{v}}$ dorsal projections and drive rhythmic activity.

PDF expression in $\mathrm{SLN}_{\mathrm{v}}$ dorsal projections is first detected in L1 larval brains (Helfrich-Förster, 1997). Since Lar participates in axon guidance through the midline during development of the embryonic CNS (Seeger et al., 1993), positioning sensory terminals in the olfactory lobe (Jhaveri et al., 2004), and proper compartmentalization of the visual system (Tayler et al., 2004), Lar could function during development, in adults, or both to promote PDF accumulation in $\mathrm{sLN}_{\mathrm{v}}$ dorsal projections. Using the Gal80 ${ }^{\text {ts }}$ TARGET system to express PDF neuron-specific Lar RNAi during development, in adults, or both, we found that Lar acts during development to enable PDF accumulation in $\mathrm{sLN}_{\mathrm{v}}$ dorsal projections (Table 3; Fig. 5). Because PDF functions to synchronize pacemaker neurons and drive behavioral outputs (Park et al., 2000; Peng et al., 2003; Lin et al., 2004; Collins et al., 2012; Cavanaugh et al., 2014), loss of PDF in $\mathrm{sLN}_{\mathrm{v}}$ dorsal projections likely accounts for the lack of activity rhythms.

Given that Lar is involved in axonal development, Lar could also be required for $\mathrm{SLN}_{\mathrm{v}}$ dorsal projection development rather than PDF accumulation per se. Indeed, $\mathrm{sLN}_{\mathrm{v}}$ dorsal processes marked by mCD8-GFP were severely disrupted or absent in PDF neuronspecific Lar RNAi knockdown flies (Fig. 6B). The lack of sLN $\mathrm{s}_{\mathrm{v}}$ dorsal projections in PDF neuron-specific Lar RNAi knockdown flies implies that Lar functions when $\mathrm{sLN}_{\mathrm{v}}$ dorsal projections are forming during or before the L1 larval stage (Helfrich-Förster, 1997). Our results suggest that loss of Lar alters $\mathrm{SLN}_{\mathrm{v}}$ axonal targeting in the dorsal protocerebrum during embryonic or early larval development, thereby impairing PDF signaling, synchronization of the circadian network, and rhythmic activity.

By eliminating $\mathrm{SLN}_{\mathrm{v}}$ dorsal projections, Lar mutants and RNAi knockdowns disrupt PDF signaling in a novel fashion; $p d f^{01}$ flies have intact $s \mathrm{LN}_{\mathrm{v}} \mathrm{s}$ but lack PDF expression and PDF neuron ablated flies eliminate $\mathrm{sLN}_{\mathrm{v}} \mathrm{s}$ entirely and lack PDF expression (Renn et al., 1999). In addition to their arrhythmic activity in DD, $p d f^{01}$ mutants and PDF neuron ablated flies lack morning activity in anticipation of lights-on and display an evening peak in activity $\sim 0.5-1 \mathrm{~h}$ earlier than wild-type flies in LD, suggesting that the loss of PDF accounts for both of these diurnal phenotypes (Renn et al., 1999). Unexpectedly, Lar RNAi knockdown flies were active in anticipation of
$\mathrm{ZT}(\mathrm{hr})$

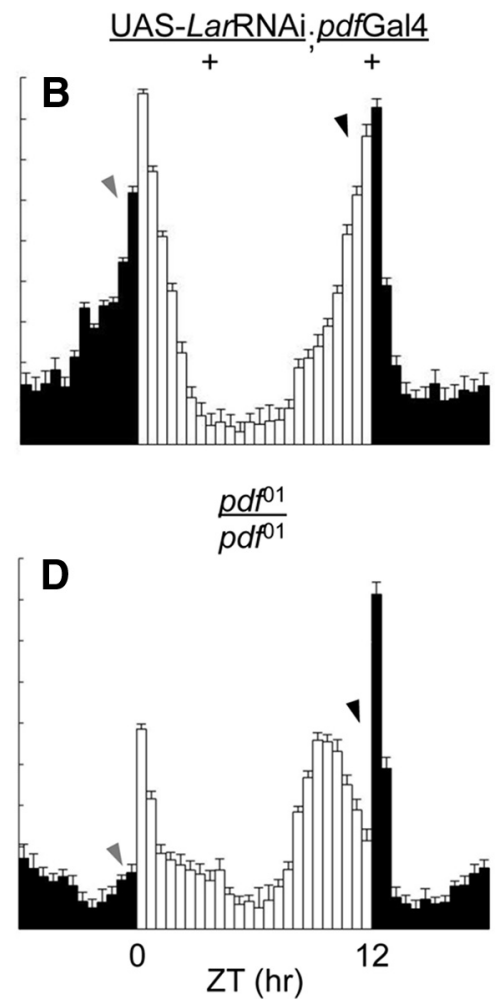

$\underline{\text { UAS-LarRNAi }}$

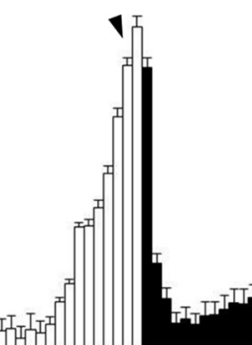

$\frac{\text { US-LarRNAi }}{\text { timGal4 }}$
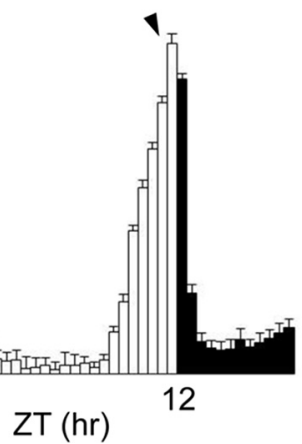

7. Activity profiles of clock-cell-specific Lar RNAi knockdown, $p d f^{01}$ and control flies during LD cycles. Average activity

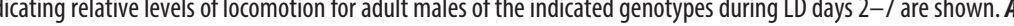

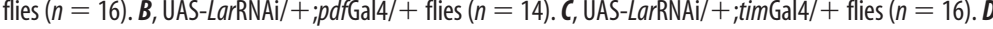
pdf mutant flies $(n=14)$. ZT time in hours during an LD cycle where lights-on is ZTO and lights-off is ZT12; white bars, daytime

Table 4. LD activity in clock-cell-specific Lar RNAi knockdown flies does not display defects seen in $p d f^{01}$ mutants

\begin{tabular}{lllll}
\hline Genotype & Total & $\begin{array}{l}\text { Evening } \\
\text { peak } \pm \text { SEM }\end{array}$ & $\begin{array}{l}\text { Morning } \\
\text { peak } \pm \text { SEM }\end{array}$ & $\begin{array}{l}\text { Anticipation } \\
\text { index } \pm \text { SEM }\end{array}$ \\
\hline$w^{1118} ;$ UAS-LarRNAi/+;+ & 16 & $12.0 \pm 0.08$ & $0.6 \pm 0.08$ & $0.79 \pm 0.04$ \\
$w^{1118} ;$ UAS-LarRNAi/timGal4;+ & 16 & $12.1 \pm 0.06^{\dagger}$ & $0.5 \pm 0.00$ & $0.95 \pm 0.03^{\wedge}$ \\
$w^{1118} ;$ UAS-LarRNAi/+;pdfGal4/+ & 14 & $12.3 \pm 0.07^{\dagger}$ & $0.5 \pm 0.04$ & $0.82 \pm 0.06^{\ddagger}$ \\
$y w^{*}+;$;pdf ${ }^{01} / p d f^{01}$ & 14 & $9.8 \pm 0.03^{*}$ & $0.6 \pm 0.08$ & $0.60 \pm 0.06^{\#}$ \\
\hline
\end{tabular}

Adult males were analyzed for behavioral rhythms during LD for at least $7 \mathrm{~d}$. The phase of activity peaks and the anticipation of lights-on during LD cycles were analyzed as described (see Materials and Methods). Total, number of flies analyzed; Morning peak \pm SEM, Zeitgeber Time of the morning activity peak \pm SEM; Evening peak \pm SEM Zeitgeber Time of the evening activity peak \pm SEM; Anticipation index \pm SEM, the amount of activity that occurs in anticipation of lights-on \pm SEM.

*Significantly different $(p<0.001)$ compared to clock-cell-specific Lar RNAi knockdown and control strains.

\#Significantly different $(p<0.05)$ compared to clock-cell-specific Lar RNAi knockdown and control strains.

${ }^{\dagger}$ Not different $(p \geq 0.07)$ than $w^{1118} ;$ UAS-LarRNAi/ $+;+$ control.

${ }^{\ddagger}$ Not different $(p=0.73)$ than $w^{1118} ;$ UAS-LarRNAi/ $+;+$ control.

${ }^{\wedge}$ Significantly better anticipation $(p=0.02)$ than $w^{1118}$;UAS-LarRNAi/+;+ control.

lights-on and showed an evening activity peak having a wild-type phase in LD cycles (Fig. 7; Table 4). Although PDF signaling to the dorsal brain is disrupted in Lar mutants and RNAi knockdowns, PDF continues to be expressed in $\operatorname{sLN}_{\mathrm{v}}$ and $\mathrm{ILN}_{\mathrm{v}}$ cell bodies and projections that target the medulla, POT and aMe (Figs. 3, 5, 6). These results imply that PDF signaling from the remaining $\mathrm{sLN}_{\mathrm{v}}$ and $\mathrm{ILN}_{\mathrm{v}}$ projections mediates normal diurnal activity with a morning (M) peak at dawn and an evening (E) peak at dusk.

In Drosophila, $\mathrm{sLN}_{\mathrm{v}} \mathrm{s}$ control the $\mathrm{M}$ activity peak and $\mathrm{LN}_{\mathrm{d}} \mathrm{s}$ plus the PDF-negative fifth $\mathrm{sLN}_{\mathrm{v}}$ control the $\mathrm{E}$ activity peak (for review, see Helfrich-Förster, 2014; Beckwith and Ceriani, 2015). Projections from the $\mathrm{M}\left(\mathrm{sLN}_{\mathrm{v}}\right)$ neurons and a subset of $\mathrm{E}\left(3 \mathrm{LN}_{\mathrm{d}}\right.$ plus fifth $\left.\mathrm{sLN}_{\mathrm{v}}\right)$ 
neurons, together with those from $\operatorname{LLN}_{\mathrm{v}} \mathrm{s}$, terminate in the aMe (Helfrich-Förster et al., 2007; Helfrich-Förster, 2014), a structure that is well preserved in Lar mutants and RNAi knockdowns. Importantly, the $\operatorname{lLN}_{\mathrm{v}} \mathrm{s}$ play a major role in conveying light input from multiple cellular sources (eg, retinal photoreceptors, HofbauerBuchner eyelets, and $\mathrm{LLN}_{\mathrm{v}} \mathrm{s}$ ) to the circadian system (HelfrichFörster et al., 2002, 2007; Shang et al., 2008; Sheeba et al., 2008; Fogle et al., 2011). PDF signaling by $\mathrm{ILN}_{\mathrm{v}} \mathrm{s}$ is known to phase advance (shorten the period) of $\mathrm{M}$ neurons and phase delay (lengthen the period) of E neurons (Wülbeck et al., 2008; Helfrich-Förster, 2014), suggesting that $\mathrm{ILN}_{\mathrm{v}} \mathrm{s}$ communicate with $\mathrm{M}$ and $\mathrm{E}$ neurons to define the pattern of diurnal activity. Consistent with this possibility, the $\mathrm{M}$ and E neurons that project into the aMe express the PDF receptor (PDFR; Im et al., 2011; Helfrich-Förster, 2014), and are thus capable of responding to PDF. Our results, together with those from previous studies, suggest a model for how diurnal rhythms are regulated; $1 L N_{v} s$ receive light input, release PDF into the aMe, PDFR receptive E cells and $M$ cells are phase delayed and phase advanced, respectively, thereby positioning the E activity peak at the lights-off transition and the M activity peak at the lights-on transition. Signaling by other neuropeptides and neurotransmitters may also be involved in mediating normal peaks of $\mathrm{M}$ and $\mathrm{E}$ activity in Lar mutant and RNAi knockdown flies (for review, see Beckwith and Ceriani, 2015), but additional studies will be necessary to define the relevant signaling pathways and targets. Because the aMe houses the circadian pacemaker center in many insects (Homberg et al., 1991; Stengl and Homberg, 1994; Frisch et al., 1996; Helfrich-Förster et al., 1998; Helfrich-Förster, 2005), it may play a conserved role in regulating diurnal activity rhythms.

LAR presumably functions to dephosphorylate substrates in $\mathrm{sLN}_{\mathrm{v}} \mathrm{s}$ that enable proper growth and targeting of dorsal projections. Previous work shows that Lar is required for segmental nerve $\mathrm{b}$ motoneuron growth cones to recognize and enter their correct target regions, suggesting that LAR regulates the phosphorylation state of intracellular target proteins critical for growth cone guidance (Krueger et al., 1996; Wills et al., 1999). It is likely that a dynamic balance of kinase and phosphatase activities at the leading edge of the growth cone endows it with the ability to integrate convergent signals and translate them into appropriate steering decisions. This suggests that Lar is a necessary component in a ligand-mediated mechanism that normally guides axons through their appropriate choice points during the development of $s \mathrm{LN}_{\mathrm{v}}$ axon architecture in the fly brain. Several LAR extracellular ligands, such as syndecan, dally like protein, and laminin-nidogen complex have been identified that contribute to motor axon guidance and synaptogenesis in flies and/or mammals (O'Grady et al., 1998; Fox and Zinn, 2005; Johnson et al., 2006). Intracellular substrates of LAR include $\beta$-catenin and p130cas, which control neurite outgrowth and apoptosis, respectively, depending on their phosphorylation state (Kypta et al., 1996; Weng et al., 1999; Xu and Fisher, 2012). Whether any of these LAR ligands or substrates contribute to $\mathrm{SLN}_{\mathrm{v}}$ dorsal projection development will require further investigation. Given that the PTP-containing intracellular domain of Drosophila LAR is $77 \%$ identical to its human ortholog (Streuli et al., 1989), it is possible that human Lar also plays a role in the development of pacemaker neuron processes in the suprachiasmatic nucleus.

\section{References}

Akten B, Jauch E, Genova GK, Kim EY, Edery I, Raabe T, Jackson FR (2003) A role for CK2 in the Drosophila circadian oscillator. Nat Neurosci 6:251257. CrossRef Medline

Akten B, Tangredi MM, Jauch E, Roberts MA, Ng F, Raabe T, Jackson FR
(2009) Ribosomal s6 kinase cooperates with casein kinase 2 to modulate the Drosophila circadian molecular oscillator. J Neurosci 29:466-475. CrossRef Medline

Andreazza S, Bouleau S, Martin B, Lamouroux A, Ponien P, Papin C, Chélot E, Jacquet E, Rouyer F (2015) Daytime CLOCK dephosphorylation is controlled by STRIPAK complexes in Drosophila. Cell Rep 11:1266-1279. CrossRef Medline

Beckwith EJ, Ceriani MF (2015) Communication between circadian clusters: the key to a plastic network. FEBS Lett 589:3336-3342. CrossRef Medline

Berke B, Wittnam J, McNeill E, Van Vactor DL, Keshishian H (2013) Retrograde BMP signaling at the synapse: a permissive signal for synapse maturation and activity-dependent plasticity. J Neurosci 33:1793717950. CrossRef Medline

Cavanaugh DJ, Geratowski JD, Wooltorton JR, Spaethling JM, Hector CE, Zheng X, Johnson EC, Eberwine JH, Sehgal A (2014) Identification of a circadian output circuit for rest:activity rhythms in Drosophila. Cell 157: 689-701. CrossRef Medline

Chiu JC, Ko HW, Edery I (2011) NEMO/NLK phosphorylates PERIOD to initiate a time-delay phosphorylation circuit that sets circadian clock speed. Cell 145:357-370. CrossRef Medline

Collins B, Kane EA, Reeves DC, Akabas MH, Blau J (2012) Balance of activity between $\mathrm{LN}(\mathrm{v})$ s and glutamatergic dorsal clock neurons promotes robust circadian rhythms in Drosophila. Neuron 74:706-718. CrossRef Medline

De J, Varma V, Saha S, Sheeba V, Sharma VK (2013) Significance of activity peaks in fruit flies, Drosophila melanogaster, under seminatural conditions. Proc Natl Acad Sci U S A 110:8984-8989. CrossRef Medline

Desai CJ, Krueger NX, Saito H, Zinn K (1997) Competition and cooperation among receptor tyrosine phosphatases control motoneuron growth cone guidance in Drosophila. Development 124:1941-1952. Medline

Dietzl G, Chen D, Schnorrer F, Su KC, Barinova Y, Fellner M, Gasser B, Kinsey K, Oppel S, Scheiblauer S, Couto A, Marra V, Keleman K, Dickson BJ (2007) A genome-wide transgenic RNAi library for conditional gene inactivation in Drosophila. Nature 448:151-156. CrossRef Medline

Fang Y, Sathyanarayanan S, Sehgal A (2007) Post-translational regulation of the Drosophila circadian clock requires protein phosphatase 1 (PP1). Genes Dev 21:1506-1518. CrossRef Medline

Fernández MP, Berni J, Ceriani MF (2008) Circadian remodeling of neuronal circuits involved in rhythmic behavior. PLoS Biol 6:e69. CrossRef Medline

Fogle KJ, Parson KG, Dahm NA, Holmes TC (2011) CRYPTOCHROME is a blue-light sensor that regulates neuronal firing rate. Science 331:14091413. CrossRef Medline

Fox AN, Zinn K (2005) The heparan sulfate proteoglycan syndecan is an in vivo ligand for the Drosophila LAR receptor tyrosine phosphatase. Curr Biol 15:1701-1711. CrossRef Medline

Frisch B, Fleissner G, Brandes C, Hall JC (1996) Staining in the brain of Pachymorpha sexguttata mediated by an antibody against a Drosophila clock-gene product: labeling of cells with possible importance for the beetle's circadian rhythms. Cell Tissue Res 286:411-429. CrossRef Medline

Glossop NR, Hardin PE (2002) Central and peripheral circadian oscillator mechanisms in flies and mammals. J Cell Sci 115:3369-3377. Medline

Hardin PE (2011) Molecular genetic analysis of circadian timekeeping in Drosophila. Adv Genet 74:141-173. CrossRef Medline

Hardin PE, Panda S (2013) Circadian timekeeping and output mechanisms in animals. Curr Opin Neurobiol 23:724-731. CrossRef Medline

Harrisingh MC, Wu Y, Lnenicka GA, Nitabach MN (2007) Intracellular $\mathrm{Ca} 2+$ regulates free-running circadian clock oscillation in vivo. J Neurosci 27:12489-12499. CrossRef Medline

Helfrich-Förster C (1997) Development of pigment-dispersing hormoneimmunoreactive neurons in the nervous system of Drosophila melanogaster. J Comp Neurol 380:335-354. CrossRef Medline

Helfrich-Förster C (2003) The neuroarchitecture of the circadian clock in the brain of Drosophila melanogaster. Microsc Res Tech 62:94-102. CrossRef Medline

Helfrich-Förster C (2005) Organization of endogenous clocks in insects. Biochem Soc Trans 33:957-961. CrossRef Medline

Helfrich-Förster C (2014) From neurogenetic studies in the fly brain to a concept in circadian biology. J Neurogenet 28:329-347. CrossRef Medline

Helfrich-Förster C, Stengl M, Homberg U (1998) Organization of the circadian system in insects. Chronobiol Int 15:567-594. CrossRef Medline

Helfrich-Förster C, Edwards T, Yasuyama K, Wisotzki B, Schneuwly S, Stanewsky R, Meinertzhagen IA, Hofbauer A (2002) The extraretinal 
eyelet of Drosophila: development, ultrastructure, and putative circadian function. J Neurosci 22:9255-9266. Medline

Helfrich-Förster C, Shafer OT, Wülbeck C, Grieshaber E, Rieger D, Taghert P (2007) Development and morphology of the clock-gene-expressing lateral neurons of Drosophila melanogaster. J Comp Neurol 500:47-70. CrossRef Medline

Homberg U, Wurden S, Dircksen H, Rao KR (1991) Comparative anatomy of pigment-dispersing hormon- immunoreactive neurons in the brain of orthopteriod insects. Cell Tissue Res 266:343-357. CrossRef

Houl JH, Ng F, Taylor P, Hardin PE (2008) CLOCK expression identifies developing circadian oscillator neurons in the brains of Drosophila embryos. BMC Neurosci 9:119. CrossRef Medline

Hyun S, Lee Y, Hong ST, Bang S, Paik D, Kang J, Shin J, Lee J, Jeon K, Hwang S, Bae E, Kim J (2005) Drosophila GPCR Han is a receptor for the circadian clock neuropeptide PDF. Neuron 48:267-278. CrossRef Medline

Im SH, Li W, Taghert PH (2011) PDFR and CRY signaling converge in a subset of clock neurons to modulate the amplitude and phase of circadian behavior in Drosophila. PLoS One 6:e18974. CrossRef Medline

Jhaveri D, Saharan S, Sen A, Rodrigues V (2004) Positioning sensory terminals in the olfactory lobe of Drosophila by Robo signaling. Development 131:1903-1912. CrossRef Medline

Johnson KG, Tenney AP, Ghose A, Duckworth AM, Higashi ME, Parfitt K, Marcu O, Heslip TR, Marsh JL, Schwarz TL, Flanagan JG, Van Vactor D (2006) The HSPGs Syndecan and Dallylike bind the receptor phosphatase LAR and exert distinct effects on synaptic development. Neuron 49:517-531. CrossRef Medline

Kaufmann N, DeProto J, Ranjan R, Wan H, Van Vactor D (2002) Drosophila liprin-alpha and the receptor phosphatase Dlar control synapse morphogenesis. Neuron 34:27-38. CrossRef Medline

Kloss B, Price JL, Saez L, Blau J, Rothenfluh A, Wesley CS, Young MW (1998) The Drosophila clock gene double-time encodes a protein closely related to human casein kinase I $\epsilon$. Cell 94:97-107. CrossRef Medline

Kloss B, Rothenfluh A, Young MW, Saez L (2001) Phosphorylation of period is influenced by cycling physical associations of double-time, period, and timeless in the Drosophila clock. Neuron 30:699-706. CrossRef Medline

Krueger NX, Van Vactor D, Wan HI, Gelbart WM, Goodman CS, Saito H (1996) The transmembrane tyrosine phosphatase DLAR controls motor axon guidance in Drosophila. Cell 84:611-622. CrossRef Medline

Kypta RM, Su H, Reichardt LF (1996) Association between a transmembrane protein tyrosine phosphatase and the cadherin-catenin complex. J Cell Biol 134:1519-1529. CrossRef Medline

Lear BC, Merrill CE, Lin JM, Schroeder A, Zhang L, Allada R (2005) A G protein-coupled receptor, groom-of-PDF, is required for PDF neuron action in circadian behavior. Neuron 48:221-227. CrossRef Medline

Lin JM, Kilman VL, Keegan K, Paddock B, Emery-Le M, Rosbash M, Allada R (2002) A role for casein kinase 2alpha in the Drosophila circadian clock. Nature 420:816-820. CrossRef Medline

Lin Y, Stormo GD, Taghert PH (2004) The neuropeptide pigmentdispersing factor coordinates pacemaker interactions in the Drosophila circadian system. J Neurosci 24:7951-7957. CrossRef Medline

Liu T, Mahesh G, Houl JH, Hardin PE (2015) Circadian activators are expressed days before they initiate clock function in late pacemaker neurons from Drosophila. J Neurosci 35:8662-8671. CrossRef Medline

Martinek S, Inonog S, Manoukian AS, Young MW (2001) A role for the segment polarity gene shaggy/GSK-3 in the Drosophila circadian clock. Cell 105:769-779. CrossRef Medline

McGuire SE, Le PT, Osborn AJ, Matsumoto K, Davis RL (2003) Spatiotemporal rescue of memory dysfunction in Drosophila. Science 302:17651768. CrossRef Medline

Menet JS, Hardin PE (2014) Circadian clocks: the tissue is the issue. Curr Biol 24:R25-R27. CrossRef Medline

Mertens I, Vandingenen A, Johnson EC, Shafer OT, Li W, Trigg JS, De Loof A, Schoofs L, Taghert PH (2005) PDF receptor signaling in Drosophila contributes to both circadian and geotactic behaviors. Neuron 48:213-219. CrossRef Medline

Nitabach MN, Taghert PH (2008) Organization of the Drosophila circadian control circuit. Curr Biol 18:R84-R93. CrossRef Medline

O'Grady P, Thai TC, Saito H (1998) The laminin-nidogen complex is a ligand for a specific splice isoform of the transmembrane protein tyrosine phosphatase LAR. J Cell Biol 141:1675-1684. CrossRef Medline

Park JH, Helfrich-Förster C, Lee G, Liu L, Rosbash M, Hall JC (2000) Dif- ferential regulation of circadian pacemaker output by separate clock genes in Drosophila. Proc Natl Acad Sci U S A 97:3608-3613. CrossRef Medline

Partch CL, Green CB, Takahashi JS (2014) Molecular architecture of the mammalian circadian clock. Trends Cell Biol 24:90-99. CrossRef Medline

Peng Y, Stoleru D, Levine JD, Hall JC, Rosbash M (2003) Drosophila freerunning rhythms require intercellular communication. PLoS Biol 1:E13. CrossRef Medline

Peschel N, Helfrich-Förster C (2011) Setting the clock-by nature: circadian rhythm in the fruitfly Drosophila melanogaster. FEBS Lett 585:1435-1442. CrossRef Medline

Pfeiffenberger C, Lear BC, Keegan KP, Allada R (2010) Sleep and circadian behavior monitoring in Drosophila. In: Drosophila neurobiology: a laboratory manual (Zhang B, Freeman MR, Waddell S, eds), pp 483-504. New York: Cold Spring Harbor.

Price JL, Blau J, Rothenfluh A, Abodeely M, Kloss B, Young MW (1998) double-time is a novel Drosophila clock gene that regulates PERIOD protein accumulation. Cell 94:83-95. CrossRef Medline

Renn SC, Park JH, Rosbash M, Hall JC, Taghert PH (1999) A pdf neuropeptide gene mutation and ablation of PDF neurons each cause severe abnormalities of behavioral circadian rhythms in Drosophila. Cell 99:791-802. CrossRef Medline

Sathyanarayanan S, Zheng X, Xiao R, Sehgal A (2004) Posttranslational regulation of Drosophila PERIOD protein by protein phosphatase 2A. Cell 116:603-615. CrossRef Medline

Seeger M, Tear G, Ferres-Marco D, Goodman CS (1993) Mutations affecting growth cone guidance in Drosophila: genes necessary for guidance toward or away from the midline. Neuron 10:409-426. CrossRef Medline

Shafer OT, Yao Z (2014) Pigment-dispersing factor signaling and circadian rhythms in insect locomotor activity. Curr Opin Insect Sci 1:73-80. CrossRef Medline

Shang Y, Griffith LC, Rosbash M (2008) Light-arousal and circadian photoreception circuits intersect at the large PDF cells of the Drosophila brain. Proc Natl Acad Sci U S A 105:19587-19594. CrossRef Medline

Sheeba V, Fogle KJ, Kaneko M, Rashid S, Chou YT, Sharma VK, Holmes TC (2008) Large ventral lateral neurons modulate arousal and sleep in Drosophila. Curr Biol 18:1537-1545. CrossRef Medline

Stengl M, Homberg U (1994) Pigment-dispersing hormone-immunoreactive neurons in the cockroach Leucophaea maderae share properties with circadian pacemaker neurons. J Comp Physiol A 175:203-213. CrossRef Medline

Streuli M, Krueger NX, Tsai AY, Saito H (1989) A family of receptor-linked protein tyrosine phosphatases in humans and Drosophila. Proc Natl Acad Sci U S A 86:8698-8702. CrossRef Medline

Szabó A, Papin C, Zorn D, Ponien P, Weber F, Raabe T, Rouyer F (2013) The CK2 kinase stabilizes CLOCK and represses its activity in the Drosophila circadian oscillator. PLoS Biol 11:e1001645. CrossRef Medline

Tayler TD, Robichaux MB, Garrity PA (2004) Compartmentalization of visual centers in the Drosophila brain requires slit and Robo proteins. Development 131:5935-5945. CrossRef Medline

Weng LP, Wang X, Yu Q (1999) Transmembrane tyrosine phosphatase LAR induces apoptosis by dephosphorylating and destabilizing p130Cas. Genes Cells 4:185-196. CrossRef Medline

Wills Z, Bateman J, Korey CA, Comer A, Van Vactor D (1999) The tyrosine kinase $\mathrm{Abl}$ and its substrate enabled collaborate with the receptor phosphatase Dlar to control motor axon guidance. Neuron 22:301-312. CrossRef Medline

Wülbeck C, Grieshaber E, Helfrich-Förster C (2008) Pigment-dispersing factor (PDF) has different effects on Drosophila's circadian clocks in the accessory medulla and in the dorsal brain. J Biol Rhythms 23:409-424. CrossRef Medline

Xu Y, Fisher GJ (2012) Receptor type protein tyrosine phosphatases (RPTPs): roles in signal transduction and human disease. J Cell Commun Signal 6:125-138. CrossRef Medline

Yoshii T, Rieger D, Helfrich-Förster C (2012) Two clocks in the brain: an update of the morning and evening oscillator model in Drosophila. Prog Brain Res 199:59-82. CrossRef Medline

Yu W, Zheng H, Houl JH, Dauwalder B, Hardin PE (2006) PER-dependent rhythms in CLK phosphorylation and E-box binding regulate circadian transcription. Gene Dev 20:723-733. CrossRef Medline

Yu W, Houl JH, Hardin PE (2011) NEMO kinase contributes to core period determination by slowing the pace of the Drosophila circadian oscillator. Curr Biol 21:756-761. CrossRef Medline 